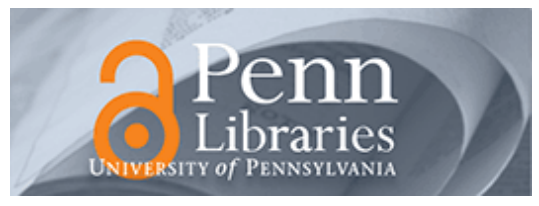

University of Pennsylvania

ScholarlyCommons

Finance Papers

Wharton Faculty Research

8-2016

\title{
Agency Selling or Reselling? Channel Structures in Electronic Retailing
}

Vibhanshu Abhishek

Kinshuk Jerath

netessin@wharton.upenn.edu

Z. JOHN ZHANG

the wharton school of business

Follow this and additional works at: https://repository.upenn.edu/fnce_papers

Part of the Business Administration, Management, and Operations Commons, E-Commerce Commons, and the Finance and Financial Management Commons

Recommended Citation

Abhishek, V., Jerath, K., \& ZHANG, Z. J. (2016). Agency Selling or Reselling? Channel Structures in

Electronic Retailing. Management Science, 62 (8), 2259-2280. http://dx.doi.org/10.1287/mnsc.2015.2230

This paper is posted at ScholarlyCommons. https://repository.upenn.edu/fnce_papers/140

For more information, please contact repository@pobox.upenn.edu. 


\title{
Agency Selling or Reselling? Channel Structures in Electronic Retailing
}

\begin{abstract}
In recent years, online retailers (also called e-tailers) have started allowing manufacturers direct access to their customers while charging a fee for providing this access, a format commonly referred to as agency selling. In this paper, we use a stylized theoretical model to answer a key question that e-tailers are facing: When should they use an agency selling format instead of using the more conventional reselling format? We find that agency selling is more efficient than reselling and leads to lower retail prices; however, the etailers end up giving control over retail prices to the manufacturer. Therefore, the reaction by the manufacturer, who makes electronic channel pricing decisions based on their impact on demand in the traditional channel (brick-and-mortar retailing), is an important factor for e-tailers to consider. We find that when sales in the electronic channel lead to a negative effect on demand in the traditional channel, etailers prefer agency selling, whereas when sales in the electronic channel lead to substantial stimulation of demand in the traditional channel, e-tailers prefer reselling. This preference is mediated by competition between e-tailers-as competition between them increases, e-tailers prefer to use agency selling. We also find that when e-tailers benefit from positive externalities from the sales of the focal product (such as additional profits from sales of associated products), retail prices may be lower under reselling than under agency selling, and the e-tailers prefer reselling under some conditions for which they would prefer agency selling without the positive externalities.
\end{abstract}

\section{Keywords}

multichannel retailing, electronic commerce, distribution channel, cross-channel spillovers, platform retailing; retail competition, game theory

\section{Disciplines}

Business | Business Administration, Management, and Operations | E-Commerce | Finance and Financial Management 


\section{Carnegie Mellon University}

Research Showcase@ CMU

Heinz College Research

Heinz College

$1-2015$

\section{Agency Selling or Reselling? Channel Structures in Electronic Retailing}

Vibhanshu Abhishek

Carnegie Mellon University, vibs@andrew.cmu.edu

Kinshuk Jerath

Columbia University

Z.John Zhang

University of Pennsylvania

Follow this and additional works at: http://repository.cmu.edu/heinzworks

Part of the Databases and Information Systems Commons, and the Public Policy Commons

This Working Paper is brought to you for free and open access by the Heinz College at Research Showcase@ CMU. It has been accepted for inclusion in Heinz College Research by an authorized administrator of Research Showcase @ CMU. For more information, please contact research-

showcase@andrew.cmu.edu. 


\title{
Agency Selling or Reselling? \\ Channel Structures in Electronic Retailing
}

\author{
Vibhanshu Abhishek, Kinshuk Jerath, Z. John Zhang
}

vibs@andrew.cmu.edu, jerath@columbia.edu, zjzhang@wharton.upenn.edu

January 2015 


\title{
Agency Selling or Reselling? Channel Structures in Electronic Retailing
}

\begin{abstract}
In recent years, online retailers (e-tailers) have started allowing manufacturers direct access to their customers while charging a fee for providing this access, a format commonly referred to as agency selling. In this paper, we use a stylized theoretical model to answer a key question that e-tailers are facing: When should they use an agency selling format instead of using the more conventional reselling format? We find that agency selling is more efficient than reselling and leads to lower retail prices; however, the e-tailers end up giving control over retail prices to the manufacturer. Therefore, the reaction by the manufacturer, who makes electronic channel pricing decisions based on their impact on demand in the traditional channel (brick-and-mortar retailing), is an important factor for e-tailers to consider. We find that when sales in the electronic channel lead to a negative effect on demand in the traditional channel, e-tailers prefer agency selling, whereas when sales in the electronic channel lead to substantial stimulation of demand in the traditional channel, e-tailers prefer reselling. This preference is mediated by competition between e-tailers - as competition between them increases, e-tailers prefer to use agency selling. We also find that when e-tailers benefit from positive externalities from the sales of the focal product (such as additional profits from sales of associated products), retail prices may be lower under reselling than under agency selling, and the e-tailers prefer reselling under some conditions for which they would prefer agency selling without the positive externalities.
\end{abstract}

Keywords: multi-channel retailing, electronic commerce, distribution channel, cross-channel spillovers, agency model, retail competition, game theory. 


\section{Introduction}

Online retailing has witnessed strong growth in the last decade, and US online retail sales were reported to be $\$ 290$ billion in 2013, accounting for $9 \%$ of total US retail sales (Sehgal, 2014). Online retailers (also called "e-tailers") have primarily been resellers (i.e., e-tailers purchase from manufacturers and resell to consumers online). More recently, US e-tailers such as Amazon (through Amazon Marketplace) and Sears (through Marketplace at Sears) have broken away from the traditional reselling format and embraced the agency model. Indeed, in recent years, a large fraction of Amazon's sales and revenue have come from its Marketplace (Amazon, 2014). Prominent online retailers in other countries have also adopted agency selling, such as Taobao in China (Bonfils, 2012) and Flipkart in India (Tiwari, 2014). Under this selling format, e-tailers allow manufacturers (or, more generally, upstream agents) direct access to customers through the retailing website for a fee, and manufacturers make decisions regarding key factors such as retail prices without making investments in retail space or e-commerce websites.

Increased transparency in factors such as retail prices has led many manufacturers and content producers to enthusiastically adopt the agency selling format: book publishers such as Macmillan and Random House, and magazines such as The New Yorker, have started using Kindle and iPad extensively for distribution of their content, and app and game developers use the Android-based mobile devices and iPhone to reach out to their consumers. Nevertheless, although agency selling is becoming more popular, we observe that reselling continues to prevail as the dominant selling format in some mature digital industries such as music. In this research, we study different factors that affect the choice of selling format across different industries in the online context.

A key distinction between the reselling and agency selling formats is who sets the retail prices - in agency selling the retail prices are decided by the manufacturer, whereas in reselling they are decided by the e-tailer, - and we focus on this distinction in this paper. More specifically, in the reselling format, the e-tailer buys goods from the manufacturer at a wholesale price and sets the retail price in the market (as practiced by Amazon for many of its products, iTunes and Soap.com, among others). In the agency selling format, the manufacturer sells directly to consumers on the retailer's marketplace and sets the retail price, but needs to share a certain fraction of the revenues with the e-tailer for providing the access (as practiced by Amazon Marketplace, Kindle, iBook Store and Alice, among others).

Online retailing is still in flux, and as it grows over time and increasingly influences traditional retailing, it is important to understand which selling formats will be adopted by competing e-tailers. Interestingly, online retailers have been the primary architects of the e-channel as opposed to manufacturers in brick-and-mortar channel. Some analysts attribute this to the bargaining power they command in the e-channel due to large customer bases that span several geographies (Carr, 2012). Even though the existence of different selling formats in online retailing is a conspicuous phenomenon, the understanding of this phenomenon is limited. Our aim in this paper is to develop a deeper understanding of online retail formats, which can guide e-tailers in making the choice between using the historically dominant reselling format, and the agency selling format.

A key factor that plays a role in determining the selling format in online retailing is the degree of competition among e-tailers. Furthermore, in a multi-channel retailing environment, sales in one 
channel may have an impact on sales in another channel. Several empirical studies suggest that sales in the electronic channel have a negative effect on sales in the traditional brick-and-mortar channel (Brynjolfsson et al. (2009) and Goolsbee (2001) show this for apparel and computers, respectively). Other studies suggest that the e-channel not only gives access to new consumers, but also has a strong stimulation effect on demand in the traditional channel (Smith and Telang (2010) and Mortimer et al. (2012) show this for media, such as movies and music). Yet other studies suggest that effect of e-channel sales on traditional channel can be positive but small (Hilton and Wiley (2010) show this for books). Such cross-channel effects impact the manufacturer's aggregate profit from the two channels. In the presence of spillovers between channels, different selling formats in online retailing will induce different strategic reactions from the manufacturer, because they will lead to different levels of sales in the echannel which will impact the manufacturer's sales in the traditional channel. Moreover, these reactions from the manufacturer will affect the e-tailer's profitability as well. Therefore, when the e-tailers decide their selling formats, they will consider the reactions from the manufacturer under different kinds of spillovers. Essentially, different selling formats lead to different degrees of channel efficiency and pricing power for various players, the impact of which on players' profits varies with the type of spillover. The equilibrium market structure is a result of the complex interactions among these factors. We build a parsimonious game theory model that captures these drivers and sheds light on the reselling versus agency selling issue.

Our results show that if the e-channel has a negative cross-effect on demand in the traditional channel, it is optimal for the e-tailers to adopt the agency selling agreement. On the other hand, if the e-channel has a strong positive cross-effect on demand in the traditional channel, the e-tailers prefer to adopt the reselling agreement. These results are directionally consistent with the retailing agreements we observe in different industries, as we discuss later. We also find that as the intensity of competition among e-tailers increases, they prefer agency selling over reselling. We also show that agency selling is beneficial for consumers as prices are lower under agency selling and consumer surplus is higher.

In our main analysis, we assume that the e-retailers' decisions are driven purely by the objective of maximizing profits from the sale of products from the manufacturer. However, in some situations, the e-tailers' decisions might also be driven by other considerations such as positive externalities from sales of complementary products. An example of this is an e-tailer that sells e-books and also sells compatible e-readers (e.g., Amazon sells both e-books and the e-reader Kindle), and higher e-book sales also motivate higher e-reader sales. In other words, there is a positive externality from e-book sales, and the e-tailer may have the incentive to increase e-book sales by lowering their price at the cost of sacrificing some of the profit from e-books. On incorporating positive externalities from sales into the model, we find that retail prices may be lower under reselling than under agency selling (which is contrary to the result from the main model). We also find that the e-tailers prefer reselling under some conditions where they would prefer agency selling without the positive externalities. This offers an explanation for why, around the year 2010 when Amazon was selling the e-reader Kindle at a high price, it was using the reselling arrangement and was selling e-books even below the wholesale price at which it purchased them from publishers (Rich, 2009). 
Our research is closely related to three streams of literature: (i) interactions between the Internet and traditional channels, (ii) retail competition within a channel, and (iii) platforms and two-sided markets. We now describe how our research relates to the literature in the these areas.

A growing stream of literature looks at the interactions between traditional and electronic channels. Balasubramanian (1998) models a horizontally-differentiated traditional channel and analyzes how this channel changes in the presence of an Internet retailer. He shows that the e-tailer acts as a wedge between the competing retailers and the retailers compete with the e-tailer instead of competing with each other. Yoo and Lee (2011) extend the Balasubramanian model to account for heterogeneous customer preferences for the e-channel, and show that introduction of the e-channel does not necessarily intensify competition, a result contrary to common intuition. Chiang et al. (2003) and Zettelmeyer (2000) suggest that a manufacturer can directly sell through the e-channel to improve its bargaining position versus a traditional retailer. These papers focus on the impact on the traditional market due to the introduction of the electronic channel. Our research differs in two distinct ways. First, we focus on the equilibrium selling formats in electronic retailing in the presence of interactions with the traditional channel, as opposed to focusing on the effect of e-channel introduction on traditional retail. Second, most research in this area assumes that the e-channel cannibalizes sales from the traditional channel. Noting that several studies show that sales in the e-channel can also stimulate demand in the traditional channel, we extend the analytical literature in this area by analyzing the impact on selling formats in the e-channel under both positive and negative spillovers from the e-channel into the traditional channel.

Our work is also related to the rich stream of literature on the determinants of vertical channel structure (McGuire and Staelin, 1983, Bernheim and Whinston, 1985, Bonanno and Vickers, 1988, Moorthy, 1988, Coughlan and Wernerfelt, 1989). Coughlan and Wernerfelt (1989) and Moorthy (1988) focus on the equilibrium channel structure when the manufacturers are the architects of the channel. Recent work in channels has been motivated by the observation that retailers are increasingly gaining greater power in the channel (Iyer and Villas-Boas, 2003, Raju and Zhang, 2005, Geylani et al., 2006). Jerath and Zhang (2010) study the equilibrium channel structure when a monopolistic retailer is the architect of the channel. Specifically, they study when a traditional retailer allows manufacturers to set up stores within a store (which can be considered as the brick-and-mortar analogue to online marketplaces). Our research, however, focuses on competing retailers and inter-channel spillovers, which is important in a multi-channel setting. Various other papers analyze contracts in channels assuming the channel structure to be exogenous (Cachon and Kok, 2010, Choi, 1991, Desai et al., 2004, Jeuland and Shugan, 1983, Iyer, 1998).

A key question that we address in this paper is: When should an e-tailer use agency selling? This is related to the nascent literature on platform retailing (Jiang et al., 2011, Kwark et al., 2012, Hagiu and Wright, 2014), as the e-tailer is essentially functioning as a platform on which manufacturers interact directly with consumers and pay the e-tailer a fee. Jiang et al. (2011) consider the phenomenon of strategic underselling by agents selling on platforms under the threat of being replaced by the platform owner, while we study a completely different problem — when will a platform structure be adopted in an electronic market. Kwark et al. (2012) study the different roles online reviews play under reselling 
versus agency selling in vertically differentiated market. Online reviews increase upstream competition in case of reselling and benefit the retailer, but put a downward pressure on prices under agency selling and hurt the retailer. Hagiu and Wright (2014) find that whether the marketplace or the reseller mode is preferred depends on whether independent suppliers or the intermediary have more important information relevant to the optimal tailoring of marketing activities for each specific product.

The rest of the paper is organized as follows. In Section 2, we describe our model. In Section 3, we analyze the different selling formats that are possible, and derive the equilibrium formats that emerge in the e-channel under different conditions. In Section 4, we consider several extensions of the basic model; in one of these extensions, we include positive externalities from sales (in addition to direct profit from sales) in the objective functions of the e-tailers. In Section 5, we conclude with a discussion and suggestions for future work.

\section{Model}

We consider a manufacturer (M) who sells a product on the electronic channel (E) through two symmetric "pure play" electronic retailers (e-tailer X and e-tailer Y). Pure play implies that retailers only have an electronic/online presence. In the rest of the paper, we refer to the manufacturer as "him" and to the e-tailers as "her."

\subsection{Channel Structures}

Different market configurations are possible in this setting based on the contractual agreements between the manufacturer and the e-tailers. An e-tailer can enter into a reselling agreement (denoted by R) with the manufacturer, in which case the e-tailer purchases the product from the manufacturer at a fixed wholesale price and decides the retail price for the consumer. This is similar to the selling format that is commonly used in brick-and-mortar retailing. Alternately, the e-tailer can enter into an agency selling agreement (denoted by A) and allow the manufacturer to sell its products directly to consumers. In this arrangement, the manufacturer determines the retail price but has to pay the e-tailer a fraction $\alpha, 0 \leq \alpha \leq 1$, of its revenues as fee for accessing her customers. Such a fee structure is used by many online marketplaces, e.g., Amazon Marketplace, Travelocity, Alice, iPhone App Store, iBook Store and Kindle. ${ }^{1}$ Note that, the key distinction between the two arrangements that we focus on is whether the manufacturer or the retailer has the ability to decide price. ${ }^{2}$

\footnotetext{
${ }^{1}$ In addition to the percentage fee, marketplace providers sometimes charge the sellers a small fixed fee as well. For instance, Amazon Marketplace charges a small fee of $\$ 39$ per month to sellers who want to sell regularly over a long time horizon on its marketplace. This fee gives the sellers access to certain infrastructure services such as easy interfaces for uploading and displaying product information. Note that, because even small professional sellers have monthly sales much higher than many thousands of dollars, this small fee is, in all probability, not levied as part of a two-part tariff with the intent of coordinating the channel.

${ }^{2}$ There are other distinctions that we do not consider in this paper. For instance, who provides service and how much, and whether the service provided is observable, is an important issue (Jerath and Zhang, 2010, Jiang et al., 2011). Another important distinction, related to logistical issues, is that under reselling the e-tailer owns the inventory and is responsible for order fulfillment, whereas under agency selling the manufacturer owns the inventory and is responsible for order fulfillment. While this may not be important in the case of information goods because delivery is virtually costless, it may be important
} 
The e-tailers independently and simultaneously choose either the reselling or the agency selling format. We endow the e-tailers with the power to make this decision because online retailers have large customer bases and extensive reach which offers them substantial power in determining the selling format that they want to use. Note, however, that in making these decisions the e-tailers will consider the subsequent reactions that they expect from the manufacturer. The e-tailers' decisions lead to three possible configurations in the market:

1. RR — Both e-tailers are resellers; we name this the "wholesale" configuration.

2. RA - E-tailer $\mathrm{X}$ chooses to sell the product as a reseller and e-tailer $\mathrm{Y}$ enters into an agency selling arrangement with the manufacturer; we name this the "hybrid" configuration. Note that the RA and AR arrangements are the same as the e-tailers are indistinguishable.

3. AA - Both e-tailers enter into agency selling agreements with the manufacturer; we name this the "agency" configuration.

\subsection{Demand Specification}

\section{Electronic Channel}

We assume the two e-tailers are symmetric and differentiated, and face a linear demand system given by:

$$
q_{X}=\frac{1}{1+\beta}-\frac{1}{1-\beta^{2}} p_{X}+\frac{\beta}{1-\beta^{2}} p_{Y}, q_{Y}=\frac{1}{1+\beta}-\frac{1}{1-\beta^{2}} p_{Y}+\frac{\beta}{1-\beta^{2}} p_{X},
$$

where $q_{i}$ is the quantity of the product sold at e-tailer $i$ and $p_{i}$ is the retail price charged by e-tailer $i, i \in\{X, Y\} .^{3}$ Linear demand models have been used in the marketing and economics literatures previously to model differentiated duopolies (Shubik and Levitan, 1980, Singh and Vives, 1984, Raju el al., 1995, Jerath and Zhang, 2010). ${ }^{4}$ The demand system above gives us a model of partial competition where $\beta \in[0,1)$ is the parameter that captures the degree of differentiation between the two e-tailers. If $\beta=0$, utilities from the products are independent, and both retailers act as monopolies in their

in the case of physical goods because delivery entails a cost. We do not model this distinction between the two contractual agreements in our model and assume that fulfillment entails a costless transfer to the consumer, an assumption invoked in most previous studies on channels. We also note that sometimes variations of these basic selling formats are used, which do not have a significant impact on the basic forces at play. For instance, in a variation on reselling, e-tailers may decide the retail price and negotiate with manufacturers on percentage fees that the manufacturers will get per sale (instead of a wholesale price). Similarly, in a variation of agency selling, the manufacturers, while setting retail prices, do not have complete freedom and can only choose one of different pre-set pricing levels.

${ }^{3}$ Note that the demand system above can be rewritten in terms of the price differential between e-tailers $\mathrm{X}$ and $\mathrm{Y}$ as $q_{X}=\frac{1}{1+\beta}-\frac{1}{1+\beta} p_{X}+\frac{\beta}{1-\beta^{2}}\left(p_{Y}-p_{X}\right), q_{Y}=\frac{1}{1+\beta}-\frac{1}{1+\beta} p_{Y}+\frac{\beta}{1-\beta^{2}}\left(p_{X}-p_{Y}\right)$.

${ }^{4}$ This demand specification follows from the quadratic consumption utility of a representative consumer which is given by $U\left(q_{X}, q_{Y}\right)=q_{X}+q_{Y}-\left(q_{X}^{2}+q_{Y}^{2}+2 \beta q_{X} q_{Y}\right) / 2$. This is a special case of the quadratic utility function in Shubik and Levitan (1980). Similar quadratic utility functions have been used in Singh and Vives (1984), Raju el al. (1995) and Jerath and Zhang (2010). This utility function for a representative consumer assumes that positive non-integer amounts of each product may be consumed. As pointed out in Dixit and Stiglitz (1979) and Anderson et al. (1992), this type of a formulation for a representative consumer can be consistent with a formulation in which every individual consumer in the population consumes zero or one unit of one product. Therefore, our formulation is appropriate for a digital goods setting (in which, generally speaking, consumers may purchase only one unit of a digital good such as an e-book or a digital copy of a song). 
respective markets. As $\beta$ increase, downstream competition in the market becomes more intense. If $\beta \rightarrow 1$, the products are fully substitutable and the market becomes perfectly competitive. Intermediate values of $\beta$ represent different degrees of differentiation.

We use this particular demand specification because it has the folloowing two desirable characteristics - as the differentiation increases (i.e., value of $\beta$ decreases), the sensitivity to price, $1 /\left(1-\beta^{2}\right)$, decreases (consistent with the intuition that customers are less price sensitive for more differentiated products), and the size of the total potential market, $2 /(1+\beta)$, increases (consistent with the intuition that more differentiated products reach a wider customer base). We have also considered other popular demand systems, such as the formulation $q_{i}=1-p_{i}+\delta\left(p_{j}-p_{i}\right), i, j \in\{X, Y\}, \delta>0$. This formulation was used in Raju el al. (1995) and has the feature that, on changing $\delta$, the degree of differentiation between the products changes whereas the total market size remains constant. We find that our results stay qualitatively the same under this alternative demand formulation. (More details of the analysis are available in the Appendix.)

The differentiation between the e-tailers comes from a combination of what is sold and where it is sold, and one or both of these factors may be operative. For instance, even if the manufacturer sells the same product through the e-tailers, goods can still be differentiated from the perspective of a consumer because of various other factors at play. For example, the experience of reading an e-book on the iPad is very different from the experience of reading the same e-book on the Kindle, and this can affect consumers' preference for (and substitutability between) Apple or Amazon even though the content of the e-book stays the same. We note that this is based on horizontal differentiation, not vertical differentiation, as at the same price not all consumers will agree that one is better than the other. More broadly, differentiation between e-tailers could arise due to website layout, inertia, loyalty and membership programs, other products offered by the e-tailers, etc. Based on how salient these differences are from the consumers' perspective, the e-tailers might compete very aggressively or not so aggressively.

The total demand for the manufacturer through the electronic channel is given by $q_{E}=q_{X}+q_{Y}$. We assume that the manufacturer can reach the consumers in this electronic market only through these e-tailers, i.e., we rule out the possibility that the manufacturer sets up a direct electronic channel, as direct selling is a difficult proposition for most manufacturers.

\section{Traditional Channel}

There is an existing (traditional) retail channel where the manufacturer sells goods at a per-unit price normalized to $\$ 1$, and faces a base demand $\bar{Q}$ in the absence of the electronic channel. It is important to note that we do not assume that the manufacturer necessarily sells identical products through the two channels; he may sell the same product or different products through the two channels. For example, a publisher of books may sell e-books through the online channel and print books (same and different titles) through the traditional channel. Similarly, a music producer or artist may sell individual mp3 tracks online, and sell album CDs, concert tickets and airplay rights offline.

The sales of the product in the traditional channel are affected by the sales in the new electronic 


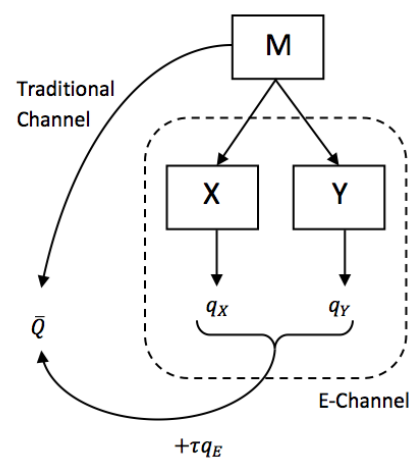

Figure 1: Market structure: Interaction of the e-channel with traditional retail.

channel. We model this by assuming that sales in the traditional channel are now $\bar{Q}+\tau q_{E}$, where $q_{E}$ denotes the total sales in the e-channel, and the parameter $\tau$ captures the net overall cross-channel effect that the e-channel imposes on sales through the existing channel. More specifically, $\tau$ represents the net change in offline sales for every unit sold online. In our analysis, we consider $\tau \in[-1,1] .{ }^{5}$ This formulation models, in a reduced-form way, an increase $(\tau>0)$, or decrease $(\tau<0)$, or no effect $(\tau=0)$ in traditional sales due to every unit sold through the e-channel. Figure 1 shows a schematic diagram explaining the cross-channel effect.

We assume a unidirectional and exogenous cross-channel effect for simplicity. In Section 4.3, we extend the model to incorporate endogenous consumer choice across the electronic and traditional channels, and show that our results remain qualitatively the same.

$\tau>0$ implies a positive cross-effect, i.e., every sale in the e-channel leads to $\tau$ units of increased sales in the traditional channel. One factor driving this increase could be word-of-mouth, e.g., when a consumer purchases an e-book on the Kindle and discusses it with his friends, they might buy the print version of the book from a bookstore. Hilton and Wiley (2010) find that availability of e-books leads to a moderate increase in the sales of print books, indicating that $\tau$ might be positive and small/moderate for books. For media products, such as movies and music, we see strong evidence of positive externalities (Smith and Telang, 2010). For example, positive cross-effects are present in the music industry in which several independent artists and, more recently, popular bands such as Coldplay, even give away their music online for free to promote concert attendance and generate demand for airplay. On the other hand, various studies also find that, in certain cases, the online channel has a negative cross-effect on sales through the traditional channel, i.e., $\tau<0$. This might be attributed to cannibalization, i.e., consumers who buy online are less likely to go into stores to buy the product, which could happen for consumer packaged goods sold at online stores like Soap.com and Alice (Brynjolfsson et al., 2009, Goolsbee, 2001). In summary, different studies show that cross-effects can be negative or positive (or absent) in different cases. Our model is flexible enough to capture all of these cross-effects and understand their implications on the selling formats that will result in the e-channel. Note that many different factors may be at play

\footnotetext{
${ }^{5}$ For $\tau<-1$, in our model, the negative externality imposed is so strong that the manufacturer would not want to sell through the electronic channel at all. Since this is an uninteresting scenario, we do not consider $\tau<1$.
} 
simultaneously in determining the aggregate effect of how demand in different channels interacts in a multi-channel scenario. ${ }^{6}$ Our reduced-form way of modeling cross-effects is meant to capture the aggregate cross-channel effect. Future research can look into the impact of different factors in isolation by micro-modeling them.

In our basic model, we also assume for simplicity that the impact on demand in the traditional channel from sales on the e-channel does not influence prices in the traditional channel. This can be due to several reasons. One reason is that the baseline demand, $\bar{Q}$, is sufficiently high compared to the magnitude of the spillover, and therefore prices are not influenced much (in support of this, note that online sales only account for about $9 \%$ of total retail sales). Other reasons can be high menu costs, established reference prices and operational reasons. For example, the prices of print books have remained largely unaffected by e-book pricing. One could argue that this is due to a combination of historically-established reference prices in the minds of consumers as well as operational difficulties (e.g., prices are printed on books and can't be changed with frequent changes in e-book prices). Nevertheles, in Section 4.2, we relax this assumption and show that the qualitative nature of the findings do not change when the prices in the traditional channel are chosen endogenously.

Given the above, the profit of the manufacturer depends on the profit from the e-channel, sales on the traditional channel and the spillover effects of the e-channel on the traditional channel, and is given by

$$
\pi_{M}=1 .\left(\bar{Q}+\tau q_{E}\right)+\pi_{M E},
$$

where $q_{E}$ is the total demand in the electronic channel and $\pi_{M E}$ is the manufacturer's profit from the electronic channel which depends on the e-channel structure-RR, RA or AA. Therefore, the manufacturer will react to the selling format in the e-channel, and the e-tailers have to consider this reaction while making their selling format decisions. A summary of notation used is presented in Table 1.

Finally, note that the insights from our model can be used to inform other multi-channel situations with cross-channel effects. However, using agency selling makes our model fairly specific to electronic channels since agency selling is not typical in other scenarios. Therefore, any extensions to other scenarios should be done with this caveat in mind.

\section{Analysis}

In this section, we characterize the equilibrium outcomes under the three configurations of the echannel - RR, RA and AA. Following this, we derive which of these configurations will be observed in equilibrium for different combinations of values of market competition $(\beta)$ and cross-channel effect $(\tau)$, and the impact on different market players of the resulting arrangement. We also derive insights for setting agency fees by e-tailers.

\footnotetext{
${ }^{6}$ The different factors at play simultaneously may include demand expansion after a new channel is introduced, a segment of consumers switching between channels due to price differences, and different products being offered on different channels (e.g., e-books through the e-channel and collector's editions through the traditional channel; music singles through the e-channel and album CDs, concert tickets and airplay rights through the other channel).
} 


\begin{tabular}{cl}
\hline Notation & Meaning \\
\hline$\beta$ & e-channel competition \\
$\tau$ & spillover effect into traditional channel \\
$p_{X}, p_{Y}$ & prices charged at the e-tailers \\
$q_{X}, q_{Y}$ & demand at the e-tailers \\
$\pi_{X}, \pi_{Y}$ & profits of the e-tailers \\
$\pi_{M E}$ & profit of the manufacturer from the e-channel \\
$\pi_{M}$ & total profit of the manufacturer \\
$\mathrm{RR}, \mathrm{RA}, \mathrm{AA}$ & e-channel configurations \\
$\alpha_{X}, \alpha_{Y}$ & fees charged by the e-tailers in the agency selling format \\
$w_{R R}^{*}, w_{R A}^{*}$ & equilibrium wholesale prices in the RR and RA configurations \\
$\alpha_{A A}^{*}, \alpha_{R A}^{*}$ & equilibriumfees charged by the e-tailers in the AA and RA configurations \\
\hline
\end{tabular}

Table 1: Notation

\subsection{Analysis of Different Configurations in the E-Channel}

\subsubsection{Electronic Channel with Two Resellers (RR)}

In this configuration, both e-tailers purchase the product at a fixed wholesale price from the manufacturer and then set retail prices. The timing of this subgame is as follows. First, the manufacturer decides the wholesale price it will charge to both e-tailers. ${ }^{7}$ The e-tailers then individually decide if they wish to accept this wholesale price or choose an outside option (which we normalize to zero). If the e-tailers accept, they set the retail prices. This arrangement is illustrated in Figure 2(a). The profits of the manufacturer and the two e-tailers are as follow:

$$
\pi_{M}^{R R}=\underbrace{1 .\left(\bar{Q}+\tau q_{E}\right)}_{\text {profits from traditional channel }}+\underbrace{w\left(q_{X}+q_{Y}\right)}_{\text {profits from }}, \quad \pi_{i}^{R R}=q_{i}\left(p_{i}-w\right), i \in\{X, Y\},
$$

where $w$ is the wholesale price, $p_{i}$ is the price charged by e-tailer $i$ and $q_{i}$ is the quantity sold by e-tailer $i$. We solve this subgame using backward induction. The equilibrium prices and quantities under this configuration are as follow:

$$
w_{R R}^{*}=\frac{1-\tau}{2}, \quad p_{X}^{R R}=p_{Y}^{R R}=\frac{3-2 \beta-\tau}{2(2-\beta)}, \quad q_{X}^{R R}=q_{Y}^{R R}=\frac{1+\tau}{2(2-\beta)(1+\beta)} .
$$

Note that the wholesale price decreases linearly with the spillover effect. This is because, if $\tau$ is negative, then more sales in the e-channel will decrease sales in the traditional channel, and the manufacturer keeps wholesale price high to induce high retail prices and sell less in the e-channel. As $\tau$ increases and

\footnotetext{
${ }^{7}$ We check that the manufacturer benefits from selling to both e-tailers as opposed to selling to only one of them.
} 


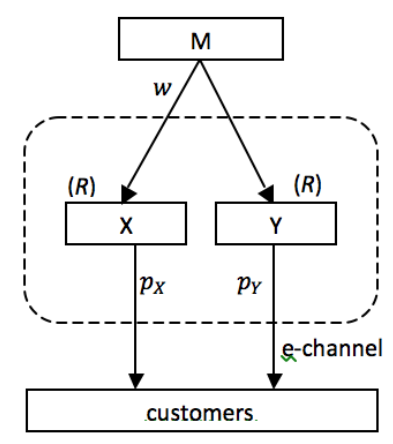

(a) Wholesale (RR) arrangement

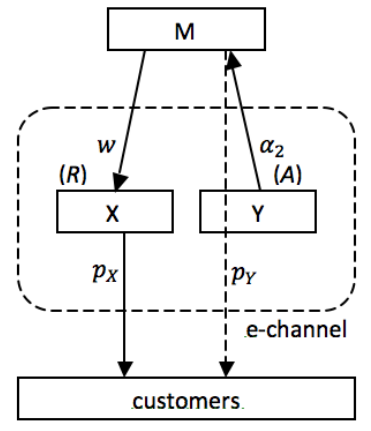

(b) Hybrid (RA) arrangement

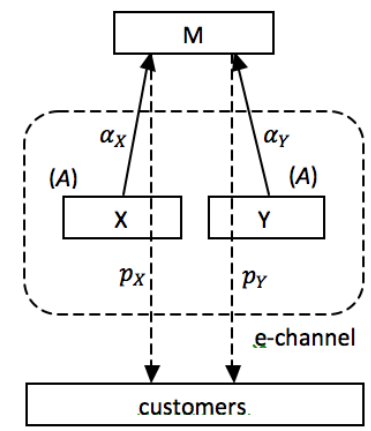

(c) Agency (AA) arrangement

Figure 2: Schematic diagrams showing the RR, RA and AA channel structures for the e-channel. M represents the manufacturer and $\mathrm{X}$ and $\mathrm{Y}$ represent the e-tailers. The direction of the arrow points away from the player making the decision. A dashed line indicates that the list price at an e-tailer in case of agency selling is decided by the manufacturer.

becomes positive, the effects are reversed and the manufacturer wants to increase sales in the e-channel by charging a low wholesale price to induce low retail prices. The equilibrium payoffs are as follow:

$$
\pi_{M}^{R R}=\frac{(1+\tau)^{2}}{2(2-\beta)(1+\beta)}, \quad \pi_{M E}^{R R}=\frac{1-\tau^{2}}{2(2-\beta)(1+\beta)}, \quad \pi_{i}^{R R}=\frac{(1-\beta)(1+\tau)^{2}}{4(2-\beta)^{2}(1+\beta)} \quad \forall i \in X, Y .
$$

It is easy to see that both $\pi_{M}^{R R}$ and $\pi_{i}^{R R}$ are convex and increasing in $\tau$ whereas $\pi_{M E}^{R R}$ is concave in $\tau$ and achieves a maximum when $\tau=0$.

\subsubsection{Electronic Channel with One Reseller and One Agency Seller (RA)}

In this configuration, one of the e-tailers uses agency selling and the other e-tailer sells as a reseller. First, the e-tailer willing to enter into an agency selling agreement announces the agency fee, $\alpha$, which is the fraction of the revenue she will keep for each item sold through the marketplace. Without loss of generality, we assume that Y uses agency selling in this configuration. Next, after observing the agency fee, the manufacturer decides whether he wants to sell through the marketplace or only through the reseller (we find that $\mathrm{M}$ always sells through the reseller). He simultaneously announces the wholesale price $w$ for the reseller $(\mathrm{X})$. Following this, $\mathrm{X}$ decides the retail price $p_{X}$ that it will charge, and the manufacturer decides the retail price $p_{Y}$ in the marketplace provided by $\mathrm{Y}$. This arrangement is illustrated in Figure 2(b). (If the timing is changed such that the manufacturer simultaneously announces the wholesale and retail prices it will charge, the results do not change qualitatively.) If $\mathrm{M}$ decides to sell through both e-tailers his profit is:

$$
\pi_{M}^{R A}=1 \cdot\left(\bar{Q}+\tau q_{E}\right)+q_{X} w+(1-\alpha) q_{Y} p_{Y}
$$


If he decides to sell only through the reseller, we assume that the price in the marketplace is such that there are no sales through the marketplace. ${ }^{8}$ In this case, the manufacturer's and the e-tailers' payoffs are given by:

$$
\pi_{M}^{R A}=1 .\left(\bar{Q}+\tau q_{X}\right)+w q_{X}, \quad \pi_{X}^{R A}=q_{X}\left(p_{X}-w\right), \quad \pi_{Y}^{R A}=\left\{\begin{array}{ll}
\alpha q_{Y} p_{Y} & \text { if M sells through Y } \\
0 & \text { otherwise }
\end{array} .\right.
$$

If the manufacturer chooses to sell through both the e-tailers, we observe the following prices in the electronic channel:

$p_{X}^{R A}=\frac{w\left(2(1-\alpha)+\beta^{2}\right)+(1-\beta)[(1-\alpha)(2+\beta)-\beta \tau]}{(1-\alpha)\left(4-\beta^{2}\right)}, \quad p_{Y}^{R A}=\frac{w(3-\alpha) \beta+(1-\beta)[(1-\alpha)(2+\beta)-2 \tau]}{(1-\alpha)\left(4-\beta^{2}\right)}$.

The optimal wholesale price for e-tailer $\mathrm{X}$ in this case, conditional on $\alpha$, is given by:

$w_{R A}^{*}=\frac{(1-\beta)\left\{(1-\alpha)(2+\beta)(4+\beta(2(1-2 \alpha)-\beta(1-\beta)))+\left(\alpha(8+2(2-\beta) \beta)-(1+\beta)\left(8+(2-\beta) \beta^{2}\right)\right) \tau\right\}}{2\left(\beta^{4}+(1-\alpha)\left((7-\alpha) \beta^{2}-8\right)\right)}$,

which is linearly increasing in $\tau$ (as in the wholesale case).

If the manufacturer chooses to sell only through the reseller, we observe the following wholesale and retail prices in the electronic channel:

$$
w_{R A}=\frac{1-\tau}{2}, \quad p_{X}^{R A}=\frac{3-\tau}{4} .
$$

Note that the optimal wholesale price above is the same as in the wholesale (RR) case.

We find that, in equilibrium, the manufacturer sells through both e-tailers. We compute the optimal fee $\alpha_{R A}^{*}$ numerically over the entire parameter space, as solving for it analytically is challenging. We observe that the wholesale price in this case is weakly lower than the wholesale prices offered in the wholesale $(\mathrm{RR})$ case, i.e., $w_{R A}^{*} \leq w_{R R}^{*}$, and the retail prices at both the e-tailers are lower than the retail prices in the wholesale case, i.e., $p_{X}^{R A}, p_{Y}^{R A} \leq p_{X}^{R R}=p_{Y}^{R R}$.

\subsubsection{Electronic Channel with Two Agency Sellers (AA)}

In this configuration, both e-tailers use agency selling. First, the e-tailers announce the fees $\alpha_{X}$ and $\alpha_{Y}$. The manufacturer then decides whether he wants to sell through $\mathrm{X}$ or $\mathrm{Y}$ or both. Once he decides which e-tailer he wants to sell through, he decides the retail prices. This arrangement is illustrated in Figure 2(c). If the manufacturer chooses both e-tailers, his profit can be written as follows:

$$
\pi_{M}^{A A}=1 .\left(\bar{Q}+\tau q_{E}\right)+\left(1-\alpha_{X}\right) q_{X} p_{X}+\left(1-\alpha_{Y}\right) q_{Y} p_{Y}
$$

If the fee charged by an e-tailer is too high, the manufacturer might decide not to use the e-tailer's marketplace for selling his products. Under this condition, when he chooses to sell only through one

\footnotetext{
${ }^{8}$ We model zero sales in the marketplace $j(\neq i)$ by setting $q_{j}=0$, or $\frac{1}{1+\beta}-\frac{1}{1-\beta^{2}} p_{j}+\frac{\beta}{1-\beta^{2}} p_{i}=0 \Rightarrow p_{j}=1-\beta+\beta p_{i}$.
} 
e-tailer (say $i$ ), his profits and the e-tailer's profits are:

$$
\pi_{M}^{A A}=1 .\left(\bar{Q}+\tau q_{i}\right)+\left(1-\alpha_{i}\right) q_{i} p_{i}, \quad \pi_{i}^{A A}=\left\{\begin{array}{ll}
\alpha_{i} q_{i} p_{i} & \text { if M sells through } i \\
0 & \text { otherwise }
\end{array} .\right.
$$

If the manufacturer chooses to sell through both e-tailers, we observe the following retail prices in the electronic channel:

$$
p_{i}^{A A}=\frac{(1-\beta)\left(\left(1-\alpha_{i}\right)^{2} \beta-\left(1-\alpha_{j}^{A}\right) \beta \tau+\left(1-\alpha_{i}^{A}\right)(2+\beta)\left(1-\alpha_{j}^{A}+\tau\right)\right)}{4\left(1-\alpha_{i}^{A}\right)\left(1-\alpha_{j}^{A}\right)-\left(2-\alpha_{i}^{A}-\alpha_{j}^{A}\right)^{2} \beta^{2}}, \quad i, j \in\{X, Y\}, i \neq j .
$$

In case the manufacturer wishes to sell only through e-tailer $i$, we set the quantity sold at the other e-tailer to zero, i.e., $q_{j}=0$, by using a similar treatment as in the hybrid case. The retail price in marketplace $i$ is then given by:

$$
p_{i}=\frac{1}{2}\left(1-\frac{\tau}{1-\alpha_{i}}\right) .
$$

We find that, in equilibrium, the fees are such that the manufacturer sells through both e-tailers. There is a unique and symmetric equilibrium in the fees charged by the e-tailers, given by $\alpha_{X}=\alpha_{Y}=$ $\alpha_{A A}^{*}$, where:

$$
\alpha_{A A}^{*}=1-\frac{1}{3}\left(\beta(\beta-2 \tau)+K^{1 / 3}+\frac{\beta^{4}+6 \beta \tau-4 \beta^{3} \tau-3 \tau^{2}+4 \beta^{2} \tau^{2}}{K^{1 / 3}}\right)
$$

$$
\text { and } \begin{aligned}
K= & 3 \sqrt{3} \sqrt{\left(1-\beta^{2}\right) \tau^{2}\left(\beta^{6}+2 \beta^{3}\left(5-3 \beta^{2}\right) \tau+3\left(9-11 \beta^{2}+4 \beta^{4}\right) \tau^{2}+4 \beta\left(3-2 \beta^{2}\right) \tau^{3}+\tau^{4}\right)} \\
& +\beta^{6}+9 \beta^{3} \tau-6 \beta^{5} \tau+3\left(3-2 \beta^{2}\right)^{2} \tau^{2}+\beta\left(9-8 \beta^{2}\right) \tau^{3} .
\end{aligned}
$$

The equilibrium prices and quantities as a function of agency fee are as follow:

$$
p_{i}^{A}=\frac{1-\alpha_{A A}^{*}-\tau}{2\left(1-\alpha_{A A}^{*}\right)}, \quad q_{i}^{A}=\frac{1-\alpha_{A A}^{*}+\tau}{2(1+\beta)\left(1-\alpha_{A A}^{*}\right)}, \quad \forall i \in\{X, Y\}
$$

Note that, after conditioning on the fees, the prices above do not depend directly on the level of market competition $(\beta)$. This is because the prices for both e-tailers are jointly set by the manufacturer.

We can see from (4) above that $\tau$ has two effects on the retail prices - a direct effect, and an indirect effect through $\alpha_{A A}^{*}$. The direct effect leads to the reduction of prices as $\tau$ increases, because the manufacturer wants to sell more in the e-channel to advantage of the spillover into the traditional channel. The indirect effect of $\tau$ manifests itself through $\alpha_{A A}^{*}$, which increases or decreases in $\tau$ under different conditions. When $\alpha_{A A}^{*}$ increases in $\tau$, the indirect effect leads to a further reduction in prices (beyond the direct effect). This is because a larger fee means that the manufacturer can keep lesser revenue per unit, so has the incentive to reduce the price. On the other hand, when $\alpha_{A A}^{*}$ decreases in $\tau$, the indirect effect leads to an increase in prices. This is because a smaller fee means that the 
manufacturer can keep more revenue per unit, so has the incentive to increase the price. In this case, while the overall effect of $\tau$ on the prices is a combination of these two effects, the direct effect dominates the indirect effect and prices always decrease with $\tau$. The equilibrium payoffs for the manufacturer and the retailers are as follow:

$$
\begin{aligned}
\pi_{M}^{A A} & =\bar{Q}+\frac{\left(1-\alpha_{A A}^{*}+\tau\right)^{2}}{2\left(1-\alpha_{A A}^{*}\right)(1+\beta)}, \quad \pi_{M E}^{A A}=\frac{\left(1-\alpha_{A A}^{*}\right)\left[\left(1-\alpha_{A A}^{*}\right)^{2}-\tau^{2}\right]}{2\left(1-\alpha_{A A}^{*}\right)(1+\beta)}, \\
\pi_{i}^{A A} & =\frac{\alpha_{A A}^{*}\left[\left(1-\alpha_{A A}^{*}\right)^{2}-\tau^{2}\right]}{4\left(1-\alpha_{A A}^{*}\right)^{2}(1+\beta)} \quad \forall i \in\{X, Y\} .
\end{aligned}
$$

$\tau$ has both a direct and an indirect effect (through $\alpha_{A A}^{*}$ ) on the manufacturer's total profits also. The direct effect leads to an increase in profits as $\tau$ increases. However, when $\alpha_{A A}^{*}$ increases in $\tau$, the manufacturer's profits might actually decrease because he keeps a smaller fraction of the e-channel revenue. In this case, we observe that the profits are non-monotonic in the spillover.

\begin{tabular}{lc}
\hline Quantity & Relationship \\
\hline \hline prices & $p_{X}^{A A}=p_{Y}^{A A} \leq p_{X}^{R A}, p_{Y}^{R A} \leq p_{X}^{R R}=p_{Y}^{R R}$ \\
quantities & $q_{E}^{R R} \leq q_{E}^{R A} \leq q_{E}^{A A}$ \\
wholesale prices & $w_{R A}^{*} \leq w_{R R}^{*}$ \\
manufacturer's profits & $\pi_{M}^{R A} \leq \pi_{M}^{R R}, \pi_{M}^{A A}$ \\
manufacturer's e-channel profits & $\pi_{E}^{A A} \leq \pi_{E}^{R R}$ \\
\hline
\end{tabular}

Table 2: Comparison of equilibrium outcomes under different channel structures

Before we proceed, in Table 2 we present a summary of the relationships between the different equilibrium quantities under the three different e-channel structures. To obtain a sense of consumer welfare under the different formats, we compare the prices and quantities sold in the three cases and observe that under all market conditions, the lowest prices are observed under the agency arrangement, followed by the hybrid arrangement and the wholesale arrangement has the highest prices. As a result, highest quantities are sold in the agency arrangement, followed by hybrid and finally by wholesale. The prices in agency selling are lower (as compared to reselling) because, given $\alpha$, a higher price would mean more payout to the retailer (effectively, higher marginal cost) as well as lower sales. To counteract this loss, the manufacturer lowers the price to avoid the high payout to the retailer and achieves higher sales.

\subsection{Equilibrium Selling Formats}

Using the solutions of the different sub-games studied in the previous section, we now solve the first stage of the game in which the competing e-tailers determine the selling formats they will adopt. Note that we assume that selling formats are determined before the pricing decisions (in the subgames) because it is easier for the manufacturer to change wholesale prices than it is for the e-tailers to change the selling format. In other words, the decision on the selling format is a longer-term decision than the decision on 


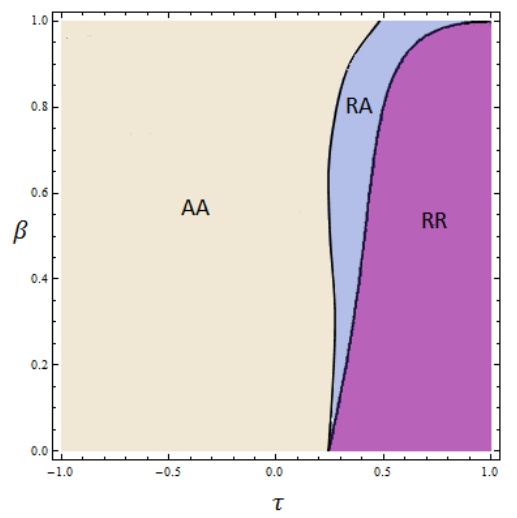

Figure 3: Equilibrium selling format as a function of cross-channel effect $(\tau)$ and retail competition $(\beta)$.

wholesale price. This timing is also in accordance with modeling choices in previous papers on vertical channel structures, e.g., (McGuire and Staelin, 1983, Moorthy, 1988, Jerath and Zhang, 2010). The following matrix represents the game between the e-tailers in strategic form (where $\pi_{X}^{A R}=\pi_{Y}^{R A}$ and $\left.\pi_{Y}^{A R}=\pi_{X}^{R A}\right)$.

\begin{tabular}{ccccc} 
& \multicolumn{2}{c}{ E-tailer Y } \\
& & \multicolumn{2}{c}{$\mathrm{A}$} & \multicolumn{2}{c}{$\mathrm{R}$} \\
\cline { 3 - 4 } E-tailer X & $\mathrm{A}$ & $\pi_{X}^{A A}, \pi_{Y}^{A A}$ & $\pi_{X}^{A R}, \pi_{Y}^{A R}$ \\
\cline { 3 - 4 } & $\mathrm{R}$ & $\pi_{X}^{R A}, \pi_{Y}^{R A}$ & $\pi_{X}^{R R}, \pi_{Y}^{R R}$ \\
\cline { 3 - 4 } & & &
\end{tabular}

Note that we have only two exogenous parameters $-\beta$ and $\tau$. We solve the preceding $2 \times 2$ game for every tuple $(\beta, \tau)$ to derive the selling formats adopted by the e-tailers in equilibrium. From the etailers' perspectives, different formats offer them varying levels of channel efficiency and pricing power. The resulting equilibrium configuration depends on the degree of competition and the cross-channel spillover. The equilibrium selling formats for all allowable values of $\beta$ and $\tau$ are described in the following proposition and illustrated in Figure 3.

Proposition 1 For any given $\beta$, both e-tailers prefer agency selling for negative or low positive spillovers, both e-tailers prefer reselling for high positive spillovers, and one e-tailer prefers agency selling with the other preferring reselling for medium positive spillovers.

We now discuss the insights behind this pattern. First, different selling formats lead to different channel efficiency. In reselling, the manufacturer sets the wholesale price, followed by each e-tailer setting her retail price, which leads to the problem of double marginalization. In agency selling, where a percentage fee structure is used, if the manufacturer sets a higher retail price, he also has to pay a larger amount as fee to the e-tailer, which leads to a downward pressure on prices. In other words, the problem of double marginalization is reduced in the case of agency selling, and the channel is more 
efficient as compared to the reselling agreement. If there were no spillover effects, the e-tailers would always prefer the agency selling format.

When faced with spillovers, the incentives of the manufacturer and the e-tailers are further misaligned due to another reason. This is because the manufacturer wants to maximize profits keeping both channels (electronic and traditional) in mind, whereas the pure-play e-tailers want to maximize the profits they derive from the electronic channel alone. In the case of a negative cross-effect of echannel sales on traditional channel sales, the manufacturer has the incentive to limit e-channel sales. Therefore, if a reselling agreement is chosen, the manufacturer will set a high wholesale price for the e-tailer which, in turn, will lead to higher retail prices and limit the negative spillover into the traditional channel. However, this implies that the double marginalization problem will worsen in the e-channel. Therefore, the e-tailers have the incentive to choose agency selling which increases channel efficiency, as discussed above. In addition, the e-tailers can also charge lower fees for access to the marketplace, which gives the manufacturer greater incentive to sell through the e-channel. Therefore, if e-channel sales have a negative cross-effect on traditional channel sales, the e-tailers will prefer agency selling.

When e-channel sales lead to a positive cross-effect on traditional sales, the manufacturer has the incentive to increase e-channel sales through lower e-channel prices. In the agency arrangement, the manufacturer has control over the retail price, and will charge a retail price lower than the efficient retail price of the e-channel. This reduces the e-tailers' realized fees as well, and hurts their profits. On the other hand, in reselling, not only do the e-tailers control the final retail price, the manufacturer is willing to charge lower wholesale prices to the e-tailers to keep retail prices low. Therefore, if the spillover effect is positive and large, the e-tailers prefer the reselling agreement.

Finally, when the spillover effect is positive and medium, the channel structure is mixed, which is surprising because ex-ante symmetric e-tailers use asymmetric channel structures. In the mixed structure, the agency format maintains efficiency, while reselling format prevents retail prices from going too low in the e-channel.

To summarize, depending on the cross-channel effect (which determines how the manufacturer will respond in prices), the e-tailers either prefer to have a more efficient vertical channel by using agency selling, or have increased pricing power by using reselling.

The results in Proposition 1 are consistent with observed selling formats in certain industries. Specifically, we find that agency selling should be preferred under a negative or small positive cross-effect. In the travel industry, where we can expect a negative effect on traditional sales (e.g., sales through travel agents or hotels) as online sales increase, we see that most online travel sites such as Expedia and Travelocity have agency selling agreements with airlines and hotels, which set retail prices. In the case of books, where the cross-effect is small positive (Hilton and Wiley, 2010), our model again predicts that we should observe agency selling, which is indeed the format used by competing e-book stores run by Amazon and Apple. On the other hand, we find that reselling should be preferred under a positive cross-effect. In industries such as music, where there are strong stimulation effects (e.g., more song and album sales lead to more revenues to artists from other channels, such as more airplay and concert collections), we observe that most online music stores, e.g., iTunes and Spotify, have a reselling 
agreement with artists and record labels. ${ }^{9}$

We now discuss how the selling formats in the e-channel vary with the intensity of competition in the market. In the presence of competing e-tailers, an advantage of agency selling is that retail prices are jointly set for both retailers by the manufacturer, which cushions competition at the retail level. In addition, the e-tailers are Stackelberg leaders in the market, which gives them more control over the channel. Thus, we expect to see that as competition increases, agency selling will be preferred more by both e-tailers. In Figure 3, when $\tau$ takes medium and large positive values, we see that as the value of the competition parameter $\beta$ increases, the e-tailers prefer to adopt the agency configuration. (For negative and small positive values of $\tau$, the e-tailers are already in the agency configuration for all values of $\beta$.) We state this result in the proposition below.

Proposition 2 As competition in the market increases (i.e., $\beta$ increases), the e-tailers' preferences shift from reselling to agency selling. If the spillover is sufficiently positive, as competition increases, the e-tailers switch from the $R R$ arrangement to the $R A$ and the $A A$ arrangements.

We contrast this result with the results in McGuire and Staelin (1983) and Jerath and Zhang (2010). In our case, as competition increases, there is a shift away from reselling and towards agency selling. In McGuire and Staelin (1983), where competing manufacturers decide the channel structure, as competition increases, the manufacturers choose reselling (or, in their terminology, vertical separation). In Jerath and Zhang (2010), where a monopolistic retailer decides the channel structure, as competition increases, there is a shift away from the store within a store arrangement (which is the brick-and-mortar analogue of agency selling). Thus, our result complements the findings in these papers.

Interestingly, under conditions of moderate spillover, we see a hybrid channel structure even though the e-tailers are ex-ante indistinguishable. Choosing two different retail formats also helps reduce the competition between the e-tailers, ${ }^{10}$ and they make more profits than they could have if they had both chosen the same retail format. Not only does the reseller (e-tailer X) face a lower wholesale fee, but the agency seller (e-tailer Y) can also charge higher agency fee. (This explains why the manufacturer never prefers the hybrid arrangement, a fact we use in the next section.) Therefore, when the spillover is moderate, we see an asymmetric configuration in the e-channel.

\subsection{Beneficiaries Under Agency Selling}

The agency selling format confers different powers to the manufacturer and the e-tailers under different conditions, and its adoption might lead to gains or losses for the players in comparison to the reselling structure. Given that the retailers decide the equilibrium selling formats, is the manufacturer always worse off under the equilibrium selling formats in the e-channel?

\footnotetext{
${ }^{9}$ We note that these industries have complicated market structures and our model is a simplification. Nevertheless, these examples do offer directional support for the insights from our model.

${ }^{10}$ Note that the hybrid channel structure is not seen when there is no market competition, i.e., $\beta=0$, and it gains more prominence as the market competition increases. This points to the fact that the emergence of this arrangement in equilibrium is driven by competitive forces.
} 


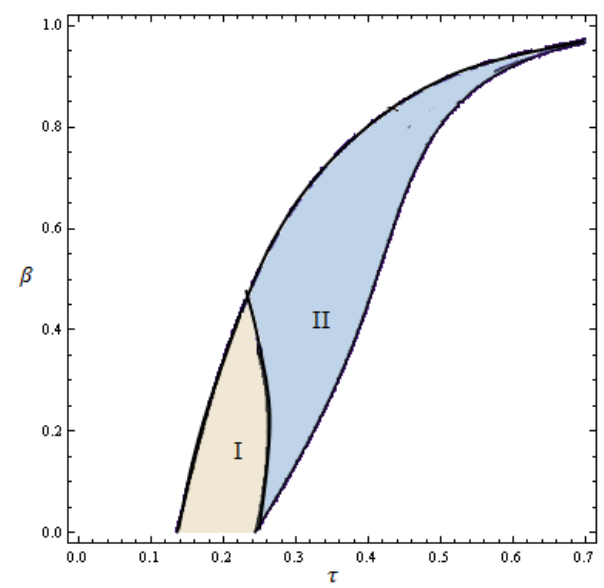

Figure 4: Manufacturer's preference for agency selling

The manufacturer is the Stackelberg leader in the reselling arrangement as it decides the wholesale prices first, while it is a Stackelberg follower in the agency arrangement as the e-tailers decide the agency fees first. Therefore, generally speaking, the manufacturer prefers the reselling arrangement. However, in the presence of spillovers, the manufacturer wants to control the final retail price in the e-channel, which implies that it has a preference for agency selling. Specifically, when the spillover is positive, the manufacturer gains more by having pricing power in the e-channel so that he can keep the price low to stimulate demand in the traditional channel and, therefore, he prefers agency selling to reselling. For a fraction of this region, the e-tailers also prefer agency selling to reselling because the gains from channel efficiency are enough to compensate for the loss of pricing power. In this situation, marked by Region I in Figure 4, the manufacturer and the e-tailers receive the highest payoff in the agency (AA) configuration as compared to any other configuration. Furthermore, in our model, consumer welfare is greater when higher quantities are sold in the market, which happens under the agency structure. Therefore, all market participants are better off with the agency structure under the conditions marked by Region I.

In the other regions in Figure 4, the equilibrium channel outcome is not what the manufacturer prefers. In Region II, the manufacturer prefers the agency (AA) structure but a hybrid structure is observed in equilibrium. (As discussed in the previous section, the manufacturer never prefers the hybrid channel arrangement.) Incidentally, if conditions in the e-book market resemble the market conditions in this region, this might provide an explanation for publishers' insistence for Amazon to adopt an agency selling format when Apple introduced agency selling in the iBook Store.

\subsection{Agency Fees under Equilibrium}

Agency selling in online marketplaces is a new retailing innovation, which is only partially understood by the industry. In this section, we provide some guidelines for setting fees under agency selling. (Note that, in this section, we analyze the fee for all combinations of values of $\beta$ and $\tau$, irrespective of whether or not agency selling will be practiced in equilibrium.) Specifically, we address how various factors such 


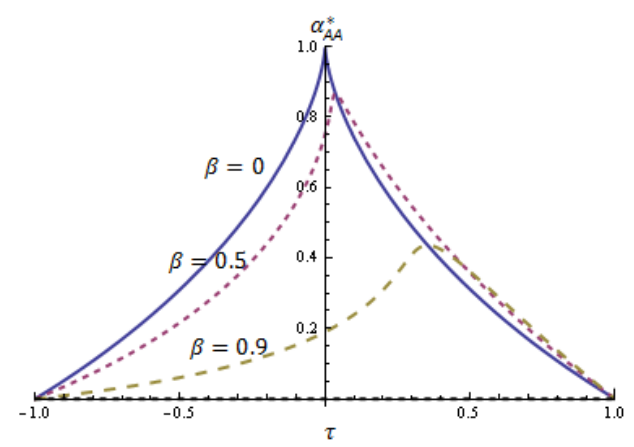

Figure 5: Changes in $\alpha_{A A}^{*}$, the fee under agency arrangement (AA) with changes in spillover effects $(\tau)$.

as spillovers and competition affect the agency fee that an e-tailer should charge.

Proposition 3 In the AA configuration, the fees charged by the e-tailers are non-monotonic in $\tau$. As $\tau$ increases from its lowest possible value of -1 , fees increase up to the value of $\tau$ at which $\left(1+\alpha_{A A}^{*}-\beta^{2}\right) \tau=$ $\left(1-\alpha_{A A}^{*}\right) \alpha_{A A}^{*} \beta$ holds. Beyond this value of $\tau$, the fees decrease in $\tau$.

The plot of $\alpha_{A A}^{*}$ is shown in Figure 5. When the e-channel has a negative cross-effect on the traditional channel, the manufacturer is cautious of selling too much in the e-channel. With a strong negative cross-effect, the e-tailers need to offer incentives to the manufacturer to sell online instead of selling through the traditional channel. They achieve this by setting a low agency fee so that the manufacturer makes a higher profit per item sold through the marketplace in comparison to the loss incurred in the traditional channel due to this sale (i.e., due to $\tau$ lower sales). As $\tau$ increases and the negative cross-effect reduces, the e-tailers need to offer smaller incentive to the manufacturer to sell through the marketplace, therefore the fee increases in $\tau$. As $\tau$ increases further and becomes sufficiently positive, the manufacturer now cares more about the stimulation of demand in the traditional channel than the revenues from the e-channel. In this case, the manufacturer can reduce prices in the marketplace to stimulate demand through the traditional channel which would result in a loss of revenue for the e-tailer offering the marketplace. Therefore, the e-tailer decreases the fee so that the manufacturer gets a bigger share of the revenues, and does not decrease retail prices in the marketplace as much.

To summarize, the fee is small for a strong negative cross-effect because the e-tailer wants the manufacturer to sell more quantity through the marketplace, it is small for a strong positive crosseffect because the e-tailer wants higher prices to be charged in the marketplace, and for intermediate cross-effect values the fee is larger than at the extremes.

We now study the effect of competition on the fee. It is natural to assume that the e-tailers would reduce the fee with increase in competition. However, we see that under some conditions the fee might actually increase with the degree of competition.

Proposition 4 In case of negative cross-effect $(\tau<0)$, the fee charged under agency selling always decreases in $\beta$. In case of positive cross-effect $(\tau>0)$, the fee first increases and then decreases in $\beta$. 


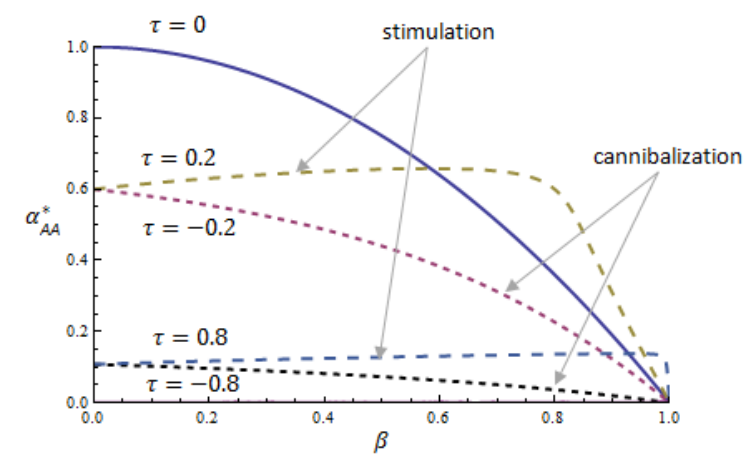

Figure 6: Changes in $\alpha_{A A}^{*}$ with market competition $(\beta)$.

The above proposition shows that the relation between the fees charged by the e-tailers and the competitive intensity in the market $(\beta)$ is mediated by the cross-channel spillover effect $(\tau)$. The first part of the proposition states that if $\beta$ increases, competition in the market increases. The etailers compete for the manufacturer's business and they need to decrease the fee to incentivize the manufacturer to use their marketplace. This is the effect for $\tau<0$.

The second part of the proposition, which states that for $\tau>0$ the fee, $\alpha_{A A}^{*}$, first increases and then decreases in $\beta$, is the more interesting case. This pattern is shown in Figure 6. This non-monotonic nature of $\alpha_{A A}^{*}$ can be explained if we consider the impact of the positive spillover from the e-channel to the traditional channel. It is clear from the demand system that, as $\beta$ increases, the sensitivity of demand to own price (given by $\left.1 /\left(1-\beta^{2}\right)\right)$ increases. In addition, the potential market size, given by $2(1 /(1+\beta))$, decreases. This implies that, all else equal, demand in the e-channel decreases as $\beta$ increases. Since $\tau>0$, the manufacturer benefits more from the positive spillover from the e-channel to the traditional channel, than from the profits in the e-channel. The decrease in e-channel demand hurts the manufacturer's profit and he reduces prices in the e-channel (as $\beta$ increases) to mitigate the fall in e-channel demand. The e-tailers foresee this drop in prices and respond by increasing the fees to get a higher share of the reduced marketplace revenues. This explains why in the presence of positive spillovers the e-tailers may increase the fee as competition between them increases. However, as $\beta$ increases further and becomes large enough, the basic effect of competition between e-tailers dominates the effect described above and leads to an overall decrease in fees in $\beta .^{11}$

We note that the non-monotonic nature of the agency fee, $\alpha_{A A}^{*}$, with respect to the parameters $\tau$ and $\beta$ is preserved in the parameter space in which the AA arrangement occurs in equilibrium. This can be easily verified by jointly viewing Figures 3,5 and 6 . Overall, the model predicts that the agency fee depends on the nature of a particular industry (specifically, competitive intensity and spillover from one channel to the other) and should, therefore, vary across industries.

\footnotetext{
${ }^{11} \alpha_{R A}^{*}$ (the agency fee in the hybrid case) changes in a manner similar to $\alpha_{A A}^{*}$.
} 


\section{Extensions}

In this section, we extend our basic model in multiple ways. First, we consider a situation in which the firm can benefit from positive externalities from sales of the product and consider the impact of this factor on pricing and channel structure. Second, we allow the manufacturer to optimally set price in the traditional channel. Third, rather than assuming a one-directional impact of online sales on offline sales, we allow both purchase decisions to influence each other.

\subsection{Positive Externality from Product Sales}

In the analysis in Section 3, we find that agency selling leads to lower prices than in reselling because it is a more efficient selling format compared to reselling. This insight may seem contradictory to the pricing practice observed in the e-book industry around the year 2010, where prices of e-books at Amazon increased after Amazon switched from reselling to agency selling. However, the driving forces discussed in our basic model are not inconsistent with this phenomenon. In this section, we show that such a phenomenon can occur when we consider additional firm incentives, thus enriching the basic model.

The e-books industry has gone through many changes in the last decade and we do not attempt to explain all the phenomena using our model. Therefore, for clarity, we first describe the phenomena in this industry that we address. Following this, we offer an explanation of these phenomena.

In the period around 2006-09, Amazon was using the reselling format for e-books and, in many cases, was selling the e-books even below the wholesale price that it paid to publishers (specifically, Amazon charged a retail price of $\$ 9.99$ for e-books whereas it typically paid publishers between $\$ 12$ and $\$ 13$ for them (Rich, 2009)). To read the e-books, consumers had to purchase the e-reader Kindle, also sold by Amazon. Notably, Amazon was making a healthy profit on Kindle. In other words, Amazon was selling e-books at a loss while making a profit through the paired-up product Kindle. Not surprisingly, the e-book publishers opposed Amazon's practice of systematically selling their e-books at very low prices (because it hurt their pricing ability in other channels) (Meadows, 2009, Rich, 2009, Trachtenberg and Blackstone, 2009). Then, in the early part of 2010, Apple released the iPad that, among other things, served as an e-reader. Apple also sold e-books from publishers through an agency selling format. Due to competition in the e-reader market (i.e., Kindle vs iPad), Amazon reduced the price of the Kindle over a period of time; in November 2008, the Kindle was priced at $\$ 399$ per unit, and by November 2012 the price had declined steadily to $\$ 79$ per unit (Yarow and Angelova, 2011). Concurrently, Amazon started moving increasingly to an agency selling setup for e-books, and also stopped selling e-books below marginal cost. Put differently,in contrast to its earlier strategy of using e-books as a loss leader, Amazon was now using the Kindle as a loss leader and making a profit on e-books (Ludwig, 2011). We now offer an explanation for these events.

In the scenario described above, before the launch of the iPad, the e-tailer's decisions are driven not only by the profits obtained from the focal product (in this case, e-books), but also by the impact of the sales of the focal product on other sources of profit in this case, profitable Kindle sales. Therefore, e-tailers may care not only about the profit generated from the product sales in the e-channel but 
also about the indirect incremental profits induced by these sales. The externalities might be driven by several underlying factors such as increased sales of associated products or long-term benefits of increased market share. Below we show that simply adding these externalities to the basic model in the Section 2 can explain the above discussed selling format choices and pricing decisions of e-tailers.

To incorporate positive externalities imposed by product sales, we modify the e-tailers' profit functions in the following manner:

$$
\tilde{\pi}_{X}^{C}=\pi_{X}^{C}+\xi q_{X}^{C} \text { and } \tilde{\pi}_{Y}^{C}=\pi_{Y}^{C}+\xi q_{Y}^{C}
$$

where the superscript $C$ denotes a particular channel configuration (i.e., RR, RA, AR or AA) and $\xi \geq 0$ denotes the positive externalities from product sales for the e-tailers. Note that the externalities might be asymmetric; however, the simpler case of symmetric externalities is sufficient for us to develop the key intuition. (For completeness, we present analysis for the asymmetric case in the Appendix.) The solution procedure for this model is the same as that in Section 3. We now discuss the insights obtained from this model.

Interestingly, if there is positive externality from product sales, situations can arise in which retail price under reselling is lower than retail price under agency selling. The intuition behind this as follows. When an e-tailer receives a positive externality from product sales, she has a greater incentive to increase her sales, i.e., she wants to sell more with the externality than she would want to sell without the externality, ceteris paribus. To sell more quantity, the retail prices charged to consumers must be lower. Consider the two selling formats, agency selling and reselling. If the selling format is agency selling, the e-tailer can decrease prices only by decreasing the agency fee she charges to the manufacturer, so that the manufacturer in turn reduces the retail price. On the other hand, if the selling format is reselling, the e-tailer can directly control retail prices which gives her greater flexibility in lowering them to drive demand.

As an example, consider an agency selling situation where the agency fee is zero and the price set by the manufacturer under agency selling is exactly the same as the wholesale price he would have charged under reselling. If the positive externality increases by a small amount, the e-tailer would want to further reduce retail prices to increase sales. However, she cannot do anything to reduce retail prices because the agency fee already equals zero and since the incentives of the manufacturer (who sets the retail price in this arrangement) have not changed, he does not change the retail price. On the other hand, in the case of reselling, the e-tailer can reduce the retail price by any desired amount to increase sales and benefit from the positive externality. Therefore, as shown by this example, with externalities due to sales, the retail price under reselling can be lower than the retail price under agency selling.

The region where the retail price under reselling is lower than that under agency selling, as a function of $\tau$ and $\beta$, is shown in Figure 7(a). We note that this is a departure from the result presented earlier in Section 3, and this difference arises due to the additional positive externality from sales that we incorporate into the basic model in this section. Interestingly, for a sufficiently high level of externality, in a reselling arrangement, the e-tailer might even reduce the retail price below the wholesale price 


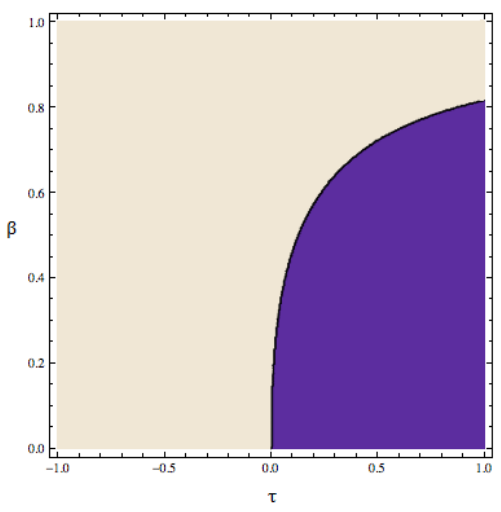

(a) In the lighter region, retail prices under reselling are lower than retail prices under agency selling.

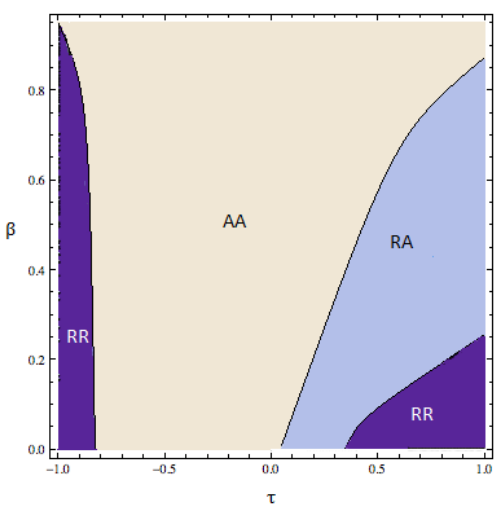

(b) Selling formats in equilibrium

Figure 7: Price comparison and equilibrium sales formats for $\xi=1$.

offered by the manufacturer. ${ }^{12}$ This offers a possible explanation for why Amazon was selling e-books below wholsale price in the reselling arrangement when Kindle prices were high, but swicthed to agency selling, which also led to an increase in e-book prices, as Kindle prices reduced.

The equilibrium selling formats with positive externalities are shown in Figure 7(b). Comparing with Figure 3, we see that the the agency selling format is more prevalent (the agency (AA) and hybrid (RA) arrangements cover larger areas) while the wholesale (RR) arrangement is less prevalent. This is because, in general, as explained earlier, prices are lower and sales are higher under agency selling, which is to the benefit of the e-tailers with positive externalities from sales. Interestingly, we see is that for large negative $\tau$ the RR arrangement prevails (whereas without positive externalities from sales, the AA arrangement prevailed in this region). The reason for this change in equilibrium channel structure is that a large negative effect on traditional sales from e-channel sales hurts the manufacturer. Under the AA arrangement, the manufacturer sets the retail prices in the e-channel to be high to limit e-channel sales, thereby limiting the negative effect on its traditional channel sales. However, the e-tailers want high e-channel sales to benefit from the positive externalities. Therefore, the e-tailers prefer to take control of the retail pricing in the e-channel by adopting the RR arrangement for large negative $\tau$, and they charge a lower retail price than what the manufacturer would charge in the agency-selling arrangement. The following proposition summarizes the above results.

Proposition 5 In the presense of positive externalities due to sales through the e-channel on the etailer's profit:

(a) Prices under reselling may be lower as compared to prices under agency selling.

(b) For any value of $\beta$, for large negative $\tau$, the wholesale (RR) arrangement emerges in equilibrium.

Before we conclude this section, we note that, in the long run, such a positive externality may reduce

\footnotetext{
${ }^{12}$ The level of externality that induces the e-tailers(s) to adopt this strategy is given by $\xi_{R R}^{*}=\frac{(1-\beta)(1+\delta)}{3-\beta}$ and $\xi_{R A}^{*}=$ $\frac{\left(1-\beta^{2}\right)\left(2+\beta^{2}-2 \alpha_{R A}^{*}\right)\left(2(1-\beta)(1+\delta)-(2(1+\delta)-\beta(3+\delta)) \alpha_{R A}^{*}-\beta \alpha_{R A}^{*}\right)}{2\left(1-\alpha_{R A}^{*}\right)\left(6\left(1-\alpha_{R A}^{*}\right)-\beta^{2}\left(6-\left(6-\alpha_{R A}^{*}\right) \alpha_{R A}^{*}\right)\right)}$, where $\xi_{R R}^{*}$ and $\xi_{R A}^{*}$ are the thresholds for the wholesale and hybrid cases, respectively.
} 
in magnitude or altogether disappear, either due to market saturation or due to shrinking profit margin from the complementary products. For instance, after the advent of the iPad and other e-readers in the market, Amazon's profit margins for the Kindle have reduced significantly, so that the positive externality from Kindle sales has reduced. In this case, our main model in which e-tailers maximize profit will be more relevant in determining long-run market outcomes. Nevertheless, it is useful to understand the (short-term) impact of such externalities on market outcomes.

The main message of this section is the following. While agency selling incentivizes a lower retail price due to channel efficiency, this does not necessarily imply that retail price under reselling cannot be lower. In fact, as the preceding analysis illustrated, if there are external influences on the incentives of the player who sets the retail price, then reselling could indeed lead to a lower retail price.

\subsection{Endogenous Pricing in the Traditional Channel}

In the analysis in Section 3, we assumed that the prices in the traditional channel are exogenously fixed. In this section, we introduce a pricing stage for the traditional channel which allows prices in the traditional channel to be determined endogenously, and to depend on the outcome of the e-channel.

Suppose that in the traditional channel the manufacturer sells his product through a reselling arrangement with a traditional retailer. He charges the traditional retailer a wholesale price $w_{o}$ and the traditional retailer sets a retail price $p_{o}$. We assume that the demand function for the traditional channel is given by $q_{o}=\bar{Q}+\tau q_{E}-p_{o}$. This is equivalent to assuming that the spillover from the e-channel changes the base demand in the traditional channel (the base demand being given by $\bar{Q}+\tau q_{E}$ ). Solving for the optimal retail and wholesale prices set by the traditional retailer and the manufacturer, respectively, we find that the manufacturer's profit is given by

$$
\pi_{M}=\frac{\left(\bar{Q}+\tau q_{E}\right)^{2}}{8}+\pi_{M E}
$$

as derived in the Appendix. $q_{E}$ and $\pi_{M E}$ are the quantity sold and the profit obtained, respectively, from the outcome in the e-channel. The above expression implies that quantity sold in the e-channel impacts the manufacturer's price and profit in the traditional channel, which, in turn, can affect the equilibrium configuration in the e-channel. We solve for the equilibria in this scenario using backward induction, and Figure 8 shows the selling formats observed in this case.

By comparing Figure 8 and Figure 3, we see that even when the prices in the traditional channel are determined endogenously, we observe outcomes qualitatively similar to those described in Proposition 1. Specifically, we observe the agency structure for negative and small positive $\tau$, the hybrid structure for medium positive $\tau$, and the wholesale structure for large positive $\tau$. The slight difference is that a smaller positive spillover $(\tau)$ is sufficient for the retailers to switch from an agency structure to a wholesale structure.

It may be the case that costs in the traditional channel are higher, such that the retailer incurs a marginal retailing cost and the manufacturer incurs a marginal production cost for goods sold via the traditional channel. For example, in the case of a printed book, the manufacturer incurs a significant cost 


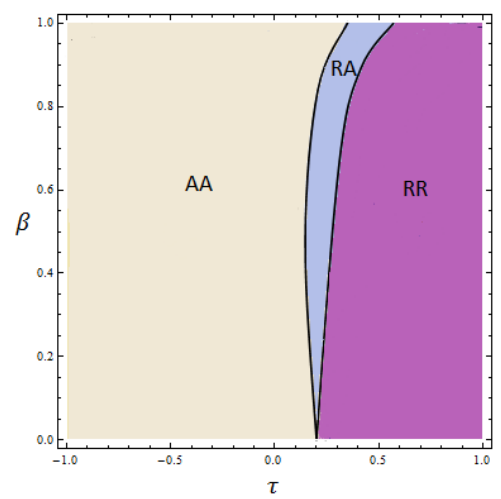

Figure 8: Channel structure when the manufacturer sells through a retailer and the prices on the traditional channel are endogenously determined $(\bar{Q}=4)$.

of printing it and the retailer incurs a significant cost of stocking it in store. Incorporating these costs does not change the results qualitatively. Furthermore, if the manufacturer sells directly to consumers in the traditional channel (rather than through a retailer) and endogenously decides prices, our results are again qualitatively unchanged. ${ }^{13}$ The main findings of our model continue to hold even if the timing of the game is changed, i.e., the price in the traditional channel are decided simultaneously or earlier than prices in the e-channel.

\subsection{Endogenous Consumer Choice Across Channels}

In the analysis in Section 3, we assumed for simplicity that the magnitude of the cross-channel effect (i.e., the effect of online sales on offline sales) is exogenous. Here, we model the cross-channel effect by modifying the utility function of the representative consumer such that the quantities consumed in the online and offline channels are decided jointly. Specifically, we use the following consumption utility function:

$$
U\left(q_{X}, q_{Y}, q_{T}\right)=q_{X}+q_{Y}+q_{T}-\frac{1}{2} q_{X}^{2}-\frac{1}{2} q_{Y}^{2}-\frac{1}{2} q_{T}^{2}-\beta q_{X} q_{Y}+\sigma q_{E} q_{T}
$$

where $q_{E}=q_{X}+q_{Y}$ denotes the total quantity consumed in the online channel. In this utility specification, $\sigma$, the coefficient of the term $q_{E} q_{T}$, is a measure of the nature and magnitude of the interaction between the sales in the traditional channel and the sales in the electronic channel. If $\sigma>0$, then there is complementarity between the two channels and if $\sigma<0$, then there is substitutability between the two channels. Using the above, we obtain the following linear demand system:

$$
\begin{aligned}
& q_{X}=\left((1+\sigma)-\frac{1-\sigma^{2}}{1-\beta} p_{X}+\frac{\beta-\sigma^{2}}{1-\beta} p_{Y}-\sigma p_{T}\right) \Omega \\
& q_{Y}=\left((1+\sigma)-\frac{\beta-\sigma^{2}}{1-\beta} p_{X}+\frac{1-\sigma^{2}}{1-\beta} p_{Y}-\sigma p_{T}\right) \Omega,
\end{aligned}
$$

\footnotetext{
${ }^{13}$ In this case, the manufacturer's profit is given by $\left(\bar{Q}+\tau q_{E}\right)^{2} / 4+\pi_{M E}$. On comparing this to (5), it is clear that the results in the two scenarios will be qualitatively similar.
} 


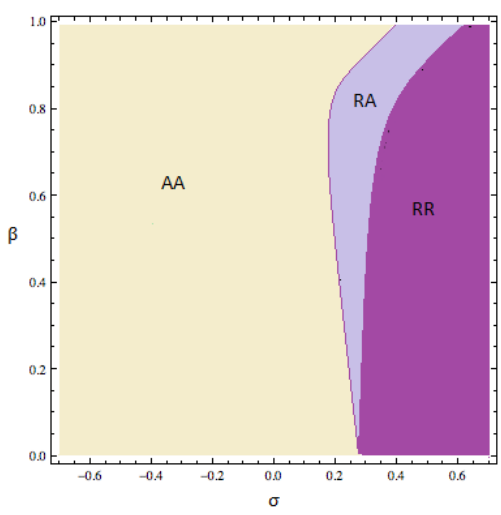

(a) Equilibrium channel configuration

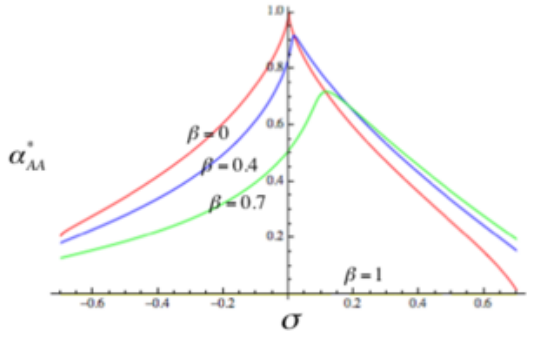

(b) Variation of agency fee with $\sigma$

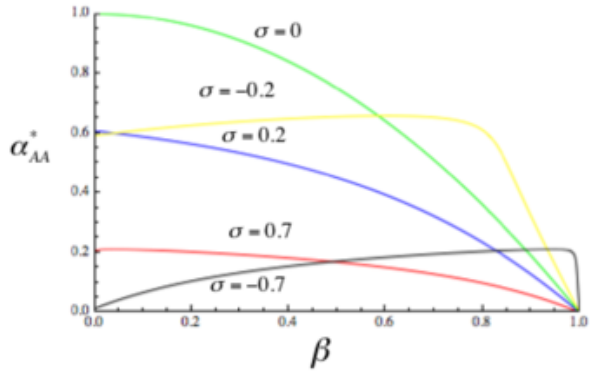

(c) Variation of agency fee with $\beta$

Figure 9: Illustrative figures for analysis with ndogenous consumer choice across channels

$$
\begin{aligned}
q_{T} & =\left((1+\beta+2 \sigma)-\sigma p_{A}-\sigma p_{B}-(1+\beta) p_{T}\right) \Omega, \\
\text { where } \Omega & =\frac{1}{1+\beta-2 \sigma^{2}} .
\end{aligned}
$$

Given the above demand system, the model can be solved using the solution procedure in Section 3 . The analysis is analytically intractable, so we resort to a numerical solution. The equilibrium selling format for different values of $\sigma$ and $\beta$ is shown in Figure 9(a). It is clear on comparing Figure 9(a) and Figure 3 that the results for the equilibrium selling formats in the current model with endogenous consumer choice across channels (where $\sigma>0$ denotes complementarity and $\sigma<0$ denotes substitutability between the channels) are qualitatively the same as those in the main model with an exogenous cross-channel effect (where $\tau>0$ denotes complementarity and $\tau<0$ denotes substitutability between the channels). In other words, the results corresponding to Propositions 1 and 2 hold in this case.

Next, we show the variation of the agency fee with $\sigma$ in Figure 9(b). This figure corresponds to Figure 5 (with $\sigma$ on the $x$-axis instead of $\tau$ ). It is easy to see that this figure is very similar to Figure 5 - the fee first increases in $\sigma$ and then decreases. This finding is consistent with Proposition 3 in the paper.

Finally, in Figure 9(c), we show the variation in the agency fee with $\beta$. This figure corresponds to Figure 6. We observe that, if $\sigma \leq 0$, the fee monotonically decreases in $\beta$, and if $\sigma>0$, the fee first increases and then decreases in $\beta$. In other words, the results of Proposition 4 are qualitatively replicated.

The key difference between the model used for this analysis and the main model is that, in the main model, for simplicity, we had assumed an exogenous and unidirectional impact of online sales on offline sales while here we develop the demand system from first priciples. As shown above, the key insights obtained from this extended model are the same as those obtained from the main model. This lends confidence to our results and shows that our main model is an appropriate and acceptable simplification. 


\section{Discussion and Conclusions}

In recent years, we have seen significant growth in the use of agency selling in e-commerce across industries. Given the proliferation of agency selling, there is a need to understand the conditions under which e-tailers should adopt them, especially keeping in mind the impact of sales in the e-channel on sales in traditional retail channels through which manufacturers also sell their products. In this paper, we identify conditions under which agency selling should be used, and the implications of using them on various market participants, i.e., competing e-tailers, manufacturers and consumers.

Our analysis suggests that agency selling is an efficient selling format, but whether an e-tailer should use it or not depends on the extent of the demand spillover between the electronic channel and the traditional channel, and on the level of competition between e-tailers. Specifically, e-tailers should use agency selling when spillovers from the electronic channel to the traditional channel are negative, absent or small positive. This result is anecdotally supported by the observation that agency selling is used by travel websites in the hotel industry (such as Expedia and Travelocity), where we can expect a significant negative effect on traditional sales (e.g., sales through travel agents) as online sales increase. As another example, the spillover effect for books has been found to be small positive (Hilton and Wiley, 2010), and large e-book sellers such as Amazon and Apple indeed use the agency model. On the other hand, setting up marketplaces and using agency selling implies giving control over retail pricing to the manufacturers. When sales in the e-channel have a large stimulation effect on sales in the traditional channel, agency selling might be detrimental for e-tailers because manufacturers have the incentive to reduce e-channel prices, which will reduce the e-tailers' revenues as well. In accordance with this prediction, we find that reselling is the dominant selling format used by online stores in the music industry (such as iTunes and Spotify), where there are strong stimulation effects on offline sales (e.g., more online sales of music singles lead to more sales of album CDs and concert tickets). These examples lend anecdotal support to our results.

Furthermore, e-tailers have greater incentive to use agency selling when there is increased competition in the market as they can control the market better by virtue of becoming Stackelberg leaders, and also partially mitigate retail competition by allowing the manufacturer to jointly set retail prices across competing e-tailers. Interestingly, we might notice a hybrid configuration in certain industries as the e-tailers adopt different selling formats to moderate intra-format competition.

We also provide directions for setting agency fees. We find that the fee in agency selling should depend both on the competition in the market and on the spillover that the e-channel has on traditional retailing. The fee charged for the use of the marketplace is small when the absolute magnitude of the spillover is large. As this magnitude of the spillover becomes smaller, implying that there is a reduction in the interaction between the two channels, the fee increases. Surprisingly, our model also shows that the fee might not always decrease with competition. When the spillover is positive, the fee might actually increase with increasing competition between the e-tailers due to the demand-stimulation effect.

Our model also provides some broader implications for the future of e-commerce. Currently, ecommerce is a small fraction of overall retailing, and we can expect both a positive or a negative spillover from online sales into traditional retailing. As e-commerce continues to grow, one can expect a 
negative spillover effect to dominate. In this case, our model predicts that we will see increased adoption of agency selling by online retailers. Furthermore, our model also predicts that if e-commerce gets more competitive over time, agency selling will increase.

We extend our basic model to assume that e-tailers may benefit from positive externalities across product sales. In this case, e-tailers may have the incentive to reduce prices to increase sales, while sacrificing direct profits from the focal product. When this holds, we find that e-tailers may prefer the reselling arrangement to maintain direct control over retail prices and reduce them appropriately to increase sales. In this case, contrary to the result of the main model, retail prices in reselling may be lower than under agency selling. This scenario with positive externalities provides an explanation for why Amazon, which selles both e-books and the e-reader Kindle, preferred reselling with low prices to agency selling when Kindle prices were high.

We assume in the model that the manufacturer directly sells through the e-tailers and the traditional channel. This is indeed true for a number of manufacturers. For instance, many e-book publishers sell directly on Amazon in agency selling and manufacturers such as Lee, Kate Spade, Burberry, US Polo Association, Lacoste and Kimberly Clark sell directly on Amazon Marketplace. However, a large number of sellers on Amazon Marketplace (and other e-tailing platforms) are not manufacturers, but are thirdparty resellers themselves. In this case, the insights from our model would be valid as long as the third-party reseller (i.e., the upstream agent) also sells in a traditional channel (which is indeed true for many sellers), and there are demand dependencies between the channels.

Our approach has several limitations which provide interesting directions for future research. First, we assume that firms do not explicitly influence how sales in the online and offline channels influence each other. It might be interesting to ascertain under what conditions manufacturers would want to promote complementarities between the two channels and under what conditions they would want sales in one channel to reduce demand in the other. In a similar vein, when a manufacturer sells different products, he can make decisions endogenously about which products to sell through different channels. Future work can advance our research by micro-modeling these factors. Second, we find that, under some conditions e-tailers choose to not offer agency selling (in spite of their efficiency) because in the presence of cross-channel spillovers they do not want to give pricing power to manufacturers. This indicates that e-tailers could benefit from using agency selling if they could impose restrictions on the retail prices that manufacturers charge. The "Most Favored Nation" agreement that Apple made with publishers of e-books is an example of this (Palazzolo, 2013). Under this agreement, the publishers could not sell the same e-book at another competitor at a price lower than at Apple's e-book store. Another example is that Apple does not give complete freedom to publishers to set prices in agency selling, and they can only choose from different pricing levels. In a similar vein, while Amazon uses agency pricing for e-books, there is compelling evidence that it attempts to influence the prices that publishers can charge (Amazon Books Team, 2014). Studying such contracts in detail, which are similar to vertical price restraints used when manufacturers control the channel (Mathewson and Winter, 1984, 1998), could be an interesting and important area for future research. Third, we have not modeled how multiple manufacturers compete on retail marketplaces. This could be an interesting direction for future 
research. Fourth, we assume a particular order of moves for the players in the model that is reasonable and justifiable. However, variation in the order of moves is possible. We consider one such variation in the timing of the game; specifically, in the asymmetric arrangement in which one e-tailer chooses reselling and the other chooses agency selling, we analyze the situation when the manufacturer is the retail price leader. We find that our main insights are robust and remain unchanged in this case, but there can also be some interesting differences in the outcomes. For instance, the asymmetric case does not occur in equilibrium (more details are available in the Appendix). Future research can explore this in more detail. Fifth, novel logistics-related agreements are being offered by e-tailers to manufacturers (such as "Fulfillment By Amazon," under which the manufacturer decides the retail price in the marketplace but the e-tailer takes over logistics activities such as warehousing and delivery). Incorporating logisticssharing aspects into our framework might lead to interesting implications. In this context, it may be important to model uncertainty in demand and understand how different risk-sharing characteristics of the different selling formats impact the e-tailers' and the manufacturers' decisions.

E-commerce presents an exciting area of research, and we believe that this is the first paper that addresses the consequences of demand spillovers between the e-channel and the traditional channel on the selling formats that emerge in electronic retailing. We hope that the ideas presented in this paper motivate interesting future research.

\section{Acknowledgements}

The authors would like to thank the anonymous reviewers, participants of Workshop on Information Systems and Economics, Marketing Science conference, and Conference on Information Systems and Technologies for several helpful suggestions. This research was partially funded by the Mack Center for Technological Innovation.

\section{References}

Simon P. Anderson, Andre de Palma and Jacques-Francois Thisse. Discrete Choice Theory of Product Differentiation. MIT Press, 1992.

Amazon. Amazon Enjoys Record-Setting Year for Marketplace Sellers Amazon PR. January 9, 2014. URL: http://phx.corporate-ir.net/phoenix.zhtml?c=176060\&p=irolnewsArticle\&ID=1889317.

Amazon Books Team. Update re: Amazon/Hachette Business Interruption Kindle Forum. July 29, $2014 . \quad$ URL: http://www. amazon.com/forum/kindle/ref=cm_cd_tfp_ef_tft_tp?_encoding=UTF8\%20\&cdForum=Fx1D7SY3B

Sridhar Balasubramanian. Mail versus Mall: A Strategic Analysis of Competition between Direct Marketers and Conventional Retailers. Marketing Science, 17(3):181-195, 1998.

B. Douglas Bernheim and Michael D. Whinston. Common Marketing Agency as a Device for Facilitating Collusion. RAND Journal of Economics, 16(2):269-281, 1985. 
Erik Brynjolfsson, Yu (Jeffrey) Hu and Mohammad S. Rahman. Battle of the Retail Channels: How Product Selection and Geography Drive Cross-Channel Competition. Management Science, 55(11): 1755-1765, 2009.

Giacomo Bonanno and John Vickers. Vertical Separation. Journal of Indistrial Economics, 36(3): 257-265, 1988.

Michael Bonfils. Taobao SEO: A Guide to One of the World's Largest Consumer Marketplaces Search Engine Watch. August 24, 2012. URL: http://searchenginewatch.com/article/2200749/TaobaoSEO-A-Guide-to-One-of-the-Worlds-Largest-Consumer-Marketplaces.

Gerard P. Cachon and A. Gurhan Kok. Competing Manufacturers in a Retail Supply Chain: On Contractual Form and Coordination. Management Science, 56(3):571-589, 2010.

David Carr. Book Publishing's Real Nemesis The New York Times. April 15, 2012. URL: http://www.nytimes.com/2012/04/16/business/media/amazon-low-prices-disguise-ahigh-cost.html.

Wei-yu Kevin Chiang, Dilip Chhajed, and James D. Hess. Direct Marketing, Indirect Profits: A Strategic Analysis of Dual-Channel Supply-Chain Design. Management Science, 49(1):pp. 1-20, 2003.

S. Chan Choi. Price Competition in a Channel Structure with a Common Retailer. Marketing Science, 10(4):271-296, 1991.

Anne T. Coughlan and Birget Wernerfelt. On Credible Delegation by Oligopolists: A Discussion of Distribution Channel Management. Management Science, 35(2):226-239, 1989.

Avinash K. Dixit and Joseph Stiglitz. Monopolistic Competition and Optimum Product Diversity: Reply. American Economic Review, 69(5):961-963, 1979.

Preyas Desai, Oded Koenigsberg and Devavrat Purohit. Strategic Decentralization and Channel Coordination. Quantitative Marketing and Economics, 2(1):5-22, 2004.

Tansev Geylani, Anthony J. Dukes and Kannan Srinivasan. Strategic Manufacturer Response to a Dominant Retailer. Marketing Science, 26(2):164-178, 2007.

Austan Goolsbee. Competition in the Computer Industry: Online versus Retail. The Journal of Industrial Economics, 49(4):487-499, 2001.

Andrei Hagiu and Julian Wright. Marketplace or Reseller? Management Science, 61(1):184-203, 2014.

John Hilton and David Wiley. The Short-Term Influence of Free Digital Versions of Books on Print Sales. The Journal of Electronic Publishing, 13 (1), 2010.

Ganesh Iyer. Coordinating Channels Under Price and Non-Price Competition. Marketing Science, 17 (4): 338-355. 1998.

Ganesh Iyer and Miguel Villas-Boas. A Bargaining Theory of Distribution Channels. Journal of Marketing Research, 40 (1): 80-100. 2003.

Kinshuk Jerath and Z. John Zhang. Store Within a Store. Journal of Marketing Research, 47(4):748-763. 2010.

Abel P. Jeuland and Steven M. Shugan. Managing Channel Profits. Marketing Science, 2(3):.239-272 1983.

Baojun Jiang, Kinshuk Jerath and Kannan Srinivasan. Firm Strategies in the "Mid-Tail" of PlatformBased Retailing. Marketing Science, 30(5):pp. 757-775, 2011.

Young Kwark, Jianqing Chen and Srinivasan Raghunathan. Platform or Wholesale: Different Effects 
on Retailers of Online Product Reviews. Proceedings of ICIS, 18(4):2012.

Sean Ludwig. Loss leader alert: $\$ 79$ Amazon Kindle costs $\$ 84$ to build. Venturebeat. November 10 , 2011. URL: http://venturebeat.com/2011/11/10/amazon-79-kindle-costs-84-to-build/.

Frank Mathewson and Ralph Winter. An Economic Theory of Vertical Restraints. RAND Journal of Economics, 15(1):27-38, 1984.

Frank Mathewson and Ralph Winter. The Law and Economics of Resale Price Maintenance. Review of Industrial Organization, 13(1-2):57-84, 1998.

Timothy W. McGuire and Richard Staelin. An Industry Equilibrium Analysis of Downstream Vertical Integration. Marketing Science, 2(2):161-191, 1983.

Chris Meadows. Amazon losing money on $\$ 9.99$ e-books. TeleRead. May 13, 2009. URL: http://www.teleread.com/ebooks/amazon-losing-money-on-999-e-books/.

K. Sridhar Moorthy. Strategic Decentralization in Channels. Marketing Science, 7(4):335-355, 1988.

Julie H. Mortimer, Chris Nosko and Alan Sorensen. Supply responses to digital distribution: Recorded music and live performances. Information Economics and Policy, 24(1):3-14, 2012.

Joe Palazzolo. Apple Ruling Heaps Doubt on 'MFN' Clauses. Wall Street Journal. July 14, 2013. URL: http://online.wsj.com/article/SB10001424127887323664204578605880157245830.html.

Eduardo Porter. Competition Needs Protection. The New York Times. April 17, 2012. URL: http://www.nytimes.com/2012/04/18/business/economy/competition-needsprotection.html.

Leena Rao. E-Commerce Spending On Black Friday Tops \$1B For The First Time; Amazon Is The Most Visited Retailer. TechCrunch November 25, 2012. URL: http://techcrunch.com/2012/11/25/ecommerce-spending-on-black-friday-tops-1b-for-the-first-time-amazon-is-the-mostvisited-retailer.

Jagmohan S. Raju, Raj Sethuraman and Sanjay K. Dhar. The Introduction and Performance of Store Brands. Management Science, 41(6):957-978, 1995.

Jagmohan S. Raju and Z. John Zhang. Channel Coordination in the Presence of a Dominant Retailer. Marketing Science, 24(2):254-262, 2003.

Mokoto Rich. Steal This Book (for \$9.99). New York Times May 16, $2009 . \quad$ URL: http://www.nytimes.com/2009/05/17/weekinreview/17rich.html?pagewanted=all\&_r=3\&.

Vikram Sehgal. Forrester Research Online Retail Forecast, 2013 To 2018. Forrester Research. URL: http://www . forrester.com/Forrester+Research+Online+Retail+Forecast+2013+To+2018+US/fulltext//E-RES115941

Martin Shubik and Richard Levitan. Market Structure and Behavior. Harvard University Press, Cambridge, MA, 1984.

Nirvikar Singh and Xavier Vives. Price and Quantity Competition in a Differentiated Duopoly. RAND Journal of Economics, 15(4):546-554, 1984.

Michael D. Smith and Rahul Telang. Piracy or Promotion? The Impact of Broadband Internet Penetration on DVD Sales. Information Economics and Policy, 22(4):289-298, 2010.

Ashish Tiwari. Flipkart to grow marketplace to compete with Amazon DNAIndia. April 17, 2014. URL: http://www.dnaindia.com/money/report-flipkart-to-grow-marketplace-tocompete-with-amazon-1979084. 
Jeffery Trachtenberg and Brian Blackstone. Book Price War Escalates. Wall Street Journal October 17, $2009 . \quad$ URL: http://online.wsj.com/news/articles/SB100014240527487043220045744777050954174722.

Wall Street Journal. The New Online Wars. Wall Street Journal. June 7, $2011 . \quad$ URL: http://online.wsj.com/article/SB10001424052702303657404576362861950356484.html.

Jay Yarow and Kamelia Angelova. Chart of the Day: When Will Kindles Be Free?. Business Insider October 17, 2009. URL: http://www.businessinsider.com/chart-of-the-day-the-shrinkingprice-of-the-kindle-2011-9? IR=T\&.

Weon Sang Yoo and Eunkyu Lee. Internet Channel Entry: A Strategic Analysis of Mixed Channel Structures. Marketing Science, 30(1):29-41, 2011.

Florian Zettelmeyer. Expanding to the Internet: Pricing and Communications Strategies When Firms Compete on Multiple Channels. Journal of Marketing Research, 37(3):292-308, 2000.

\section{Appendix}

\section{A1 Proofs for Section 3}

\section{Proofs of Propositions 1 and 2}

We use backward induction to solve for the equilibrium channel configuration. Firstly, conditional on the channel structure $(R R, R A, A A)$, we derive the equilibrium outcomes like the demand, retail prices, wholesale price and agency fees using backward induction for a specific subgame. These outcomes are presented in Section 3.1. Secondly, the equilibrium channel arrangement for every pair of $\tau$ and $\beta$ is determined by solving for the Nash equilibrium (NE) of the $2 \times 2$ game presented in Section 3.2. Note that, without loss of generality, we assume that $\mathrm{Y}$ uses agency selling in the $R A$ configuration. Solving for the NE, the platform arrangement $(A A)$ is observed when $\pi_{X}^{A A} \geq \pi_{X}^{R A}$, the hybrid arrangement $(R A)$ when $\pi_{X}^{R A} \geq \pi_{X}^{A A}$ and $\pi_{Y}^{R A} \geq \pi_{Y}^{R R}$ and the wholesale agreement $(R R)$ when $\pi_{Y}^{R R} \geq \pi_{Y}^{R A}$. It is easy to see that these conditions are mutually exclusive and there is a unique equilibrium channel structure for every pair of $\tau$ and $\beta$. Since $\alpha_{R A}^{*}$ is not analytically tractable, we resort to a numerical analysis to derive the equilibrium configuration presented in Figure 2.

\section{Proof of Proposition 3}

In order to show the variation in the platform fee w.r.t. $\tau$, we first compute the derivative of e-tailer X's profit w.r.t. the platform fee $\left(d \pi_{X}^{A A} / d \alpha_{X}\right)$, and then equate the fee charged by both e-tailers because of the symmetric equilibrium, which gives

$$
\left.\frac{d \pi_{X}^{A A}}{d \alpha_{X}}\right|_{\alpha_{X}=\alpha_{Y}=\alpha}=\frac{(1-\alpha)^{3}+\left(-2+\beta^{2}\right) \tau^{2}+(1-\alpha) \tau(2 \beta+\tau)-(1-\alpha)^{2} \beta(\beta+2 \tau)}{4(1-\alpha)^{3}\left(-1+\beta^{2}\right)} .
$$


Let $\xi(\alpha)=\frac{(1-\alpha)^{3}+\left(-2+\beta^{2}\right) \tau^{2}+(1-\alpha) \tau(2 \beta+\tau)-(1-\alpha)^{2} \beta(\beta+2 \tau)}{4(1-\alpha)^{3}\left(-1+\beta^{2}\right)}$. The F.O.C. implies that $\xi\left(\alpha_{A A}^{*}\right)=0$. Using implicit differentiation, we get

$$
\frac{\partial \alpha_{A A}^{*}}{\partial \tau}=-\frac{\partial \xi}{\partial \tau} / \frac{\partial \xi}{\partial \alpha_{A A}^{*}}=\frac{2\left(1-\alpha_{A A}^{*}\right)\left(\alpha_{A A}^{*} \beta+\tau-\beta^{2} \tau-\alpha_{A A}^{*}(\beta-\tau)\right)}{\left(2\left(2+\alpha_{A A}^{*}\right)-3 \beta^{2}\right) \tau^{2}+\left(1-\alpha_{A A}^{*}\right)^{2} \beta \alpha_{A A}^{*}{ }^{2}+2 \alpha_{A A}^{*} \beta \tau-2 \beta \tau} .
$$

Substituting the optimal fee $\left(\alpha_{A A}^{*}\right)$ in this equation, it is easy to show that the denominator is always greater than 0 for the domain of parameters, which implies $\frac{\partial \alpha_{A A}^{*}}{\partial \tau} \geq 0$ if $\tau \leq \frac{\beta \alpha_{A A}^{*}\left(1-\alpha_{A A}^{*}\right)}{1+\alpha_{A A}^{*}-\beta^{2}}$, and $\frac{\partial \alpha_{A A}^{*}}{\partial \tau}<0$ otherwise. Let $g(\tau)=\frac{\beta \alpha_{A A}^{*}\left(1-\alpha_{A A}^{*}\right)}{1+\alpha_{A A}^{*}-\beta^{2}}$. The aforementioned conditions state that $\alpha_{A A}^{*}$ is increasing in $\tau$ when $\tau \leq g(\tau)$ and decreasing when $\tau>g(\tau)$. Using Banach fixed point theorem, we can show that for every $\beta$, there is a unique $\tau^{*}$ s.t. $\tau \leq g(\tau) \forall \tau \leq \tau^{*}$ and $\tau>g(\tau)$ otherwise. Hence, $\alpha_{A A}^{*}$ increases in $\tau \leq \tau^{*}$ and decreases thereafter.

\section{Proof of Proposition 4}

Following the previous proof, we implicitly differentiate $\alpha_{A A}^{*}$ w.r.t. $\beta$ which gives us

$$
\frac{\partial \alpha_{A A}^{*}}{\partial \beta}=-\frac{\partial \xi}{\partial \beta} / \frac{\partial \xi}{\partial \alpha_{A A}^{*}}=\frac{2\left(1-\alpha_{A A}^{*}\right)\left(\tau\left(1-\beta^{2}+\alpha_{A A}^{*}\right)-\alpha_{A A}^{*} \beta\left(1-\alpha_{A A}^{*}\right)\right)}{\left(2\left(2+\alpha_{A A}^{*}\right)-3 \beta^{2}\right) \tau^{2}+\left(1-\alpha_{A A}^{*}\right)^{2} \beta \alpha_{A A}^{*}+2 \alpha_{A A}^{*} \beta \tau-2 \beta \tau} .
$$

As show in the previous proof, the denominator is always positive. Hence, the sign of $\partial \alpha_{A A}^{*} / \partial \beta$ depends on the sign of the numerator. When $\tau \leq 0$, the numerator is always negative implying that $\alpha_{A A}^{*}$ is monotonically decreasing in $\beta$. For $\tau>0, \partial \alpha_{A A}^{*} / \partial \beta>0$ when $\beta \leq\left\{\sqrt{\left(1-\alpha_{A A}^{*}\right)^{2} \alpha_{A A}^{*}{ }^{2}+4\left(1+\alpha_{A A}^{*}\right) \tau^{2}}-\left(1-\alpha_{A A}^{*}\right) \alpha_{A A}^{*}\right\} / 2 \tau$, and $\partial \alpha_{A A}^{*} / \partial \beta \leq 0$ otherwise. We can apply Banach fixed point theorem, in the manner illustrated in the proof for Proposition 3 , to show that there is a unique $\beta^{*}$ such that $\alpha_{A A}^{*}$ increases in $\beta \leq \beta^{*}$ and decreases otherwise.

\section{A2 Analysis with Asymmetric Externalities}

In this section, we analyze a case where e-tailers are asymmetric in terms of the externalities from product sales. We use the following profit functions for the e-tailers:

$$
\tilde{\pi}_{X}^{C}=\pi_{X}^{C}+\xi_{1} q_{X}^{C} \text { and } \tilde{\pi}_{Y}^{C}=\pi_{Y}^{C}+\xi_{2} q_{Y}^{C},
$$

where the superscript $C$ denotes a particular channel configuration (i.e., RR, RA, AR or AA) and $\xi_{1}$ and $\xi_{2}$ denote the positive externalities from product sales for the e-tailers. For the sake of simplicity, we assume that $\xi_{1}>\xi_{2}$ and $\xi_{2}=0$, i.e., only e-tailer $\mathrm{X}$ receives the positive externality. Under this scenario, e-tailer Y cares only about profits through the e-channel, whereas e-tailer X cares about both profits and sales. Different incentives drive different selling format choices by the e-tailers. This asymmetric model is analytically intractable, so we derive the equilibrium configuration numerically. We present the results in Figure A1 for $\xi_{1}=1$; the insights are qualitatively the same for other values of $\xi_{1}>0$. We 


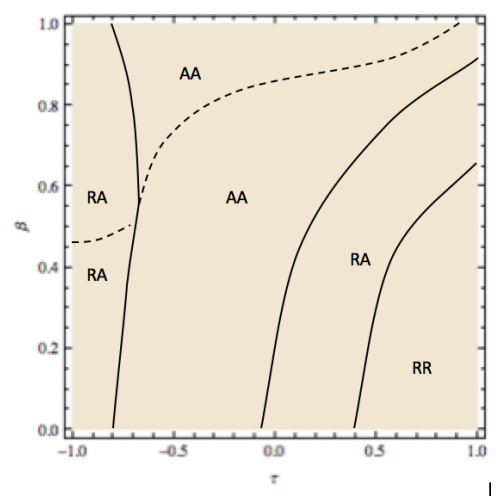

Figure A1: Channel structure when only one manufacturer receives the positive externality $\left(\xi_{1}=1, \xi_{2}=\right.$ $0)$.

obtain the following proposition, which compares the equilibrium configurations in this case to those in the case without externalities from sales.

Proposition Compared to the case without externalities from sales, for large values of $\tau$, agency selling is more dominant, as shown in Figure A1. However, when the value of $\tau$ is large negative, a hybrid arrangement is observed in equilibrium, where e-tailer $X$ is a reseller and e-tailer $Y$ is an agency seller.

As we mentioned in Proposition 1, the primary reason for the emergence of the wholesale (RR) arrangement for large positive values of $\tau$ was the mis-alignment of incentives between the manufacturer and the e-tailers - the manufacturer wanted to maximize sales on the e-channel to drive higher sales in the traditional channel, whereas the e-tailers wanted to maximize their e-channel profits. The presence of the positive externality from product sales aligns the incentives of the manufacturer and e-tailer $\mathrm{X}$ as both of them want to maximize sales through the e-channel when $\tau>0$. Therefore, in this context, the value of reselling as a strategy for the e-tailer to solve the mis-alignment issue decreases. On the other hand, for large negative values of $\tau$, the manufacturer needs a higher incentive to increase sales on the e-channel. Since the agency fee under agency selling is already very low for these values of $\tau$, the only way e-tailer $\mathrm{X}$ can incentivize the manufacturer is through a higher wholesale price under reselling. However, since e-tailer Y's incentives have not changed, she continues to use agency selling. Consequently, we observe the hybrid structure (RA) in equilibrium.

\section{A3 Derivation of Equation (5) in Section 4.2}

If the traditional retailer faces wholesale price $w_{o}$ and charges retail price $p_{o}$, her profit is $\pi_{R}=(\bar{Q}+$ $\left.\tau q_{e}-p_{o}\right)\left(p_{o}-w_{o}\right)$. The optimal retail price is $p_{o}=\left(\bar{Q}+\tau q_{e}+w_{o}\right) / 2$ and she sells a quantity $q_{o}=$ $\left(\bar{Q}+\tau q_{e}-w_{o}\right) / 2$. The manufacturer's profit from both channels is thus $\pi_{M}=\left(\bar{Q}+\tau q_{e}-w_{o}\right) w_{o} / 2+\pi_{E}$. He sets a profit maximizing wholesale price given by $w_{o}=\left(\bar{Q}+\tau q_{e}\right) / 2$ for the traditional retailer which leads to an overall profit of $\pi_{M}=\frac{\left(\bar{Q}+\tau q_{e}\right)^{2}}{8}+\pi_{E}$. 


\section{A4 Manufacturer as the Price Leader in the RA configuration}

In Section 3.1.2, we had assumed the following timing in the RA channel structure: First, the etailer willing to enter into an agency selling agreement announces the agency fee $\alpha$. Subsequently, the manufacturer decides the wholesale price. Finally, e-tailer X and the manufacturer simultaneously decide retail prices and then demand is realized.

Here, we consider a situation when the timing of the game is slightly altered. We assume that the manufacturer is the price leader in the RA case. Specifically, the order of moves is the following. First, e-tailer $\mathrm{Y}$ declares the agency fee. Next, the manufacturer sets both the wholesale price $(w)$ to be charged to e-tailer $\mathrm{X}$, and retail price $\left(p_{Y}^{R A}\right)$ at retailer $\mathrm{Y}$ simultaneously. Finally, e-tailer $\mathrm{X}$ sets the retail price. Note that in the original analysis both $p_{X}^{R A}$ and $p_{Y}^{R A}$ were decided simultaneously. In this case, the manufacturer sets the retail price at $\mathrm{Y}$ before e-tailer $\mathrm{X}$ sets its retail price, which gives it more market power. We use backward induction to derive the equilibrium outcomes. Given $w$ and $p_{Y}^{R A}$, e-tailer $\mathrm{X}$ sets a retail price equal to

$$
p_{X}^{R A}=\frac{1+w-\beta\left(1-p_{Y}^{R A}\right)}{2} .
$$

Given $\alpha$, the manufacturer simultaneously decides the wholesale and retail prices, which are as follows:

$$
\begin{aligned}
w & =\frac{(1-\beta)\left\{4(1-\alpha)+2(2-\alpha)(1-\alpha) \beta+\alpha \beta^{2}-\left[4(1-\alpha)+2(2-\alpha) \beta+\alpha \beta^{2}\right] \tau\right\}}{\left(8(1-\alpha)\left(1-\beta^{2}\right)-\alpha^{2} \beta^{2}\right.}, \\
p_{Y}^{R A} & =\frac{(1-\beta)[4(1+\beta)(1-\tau)-\alpha(4+\beta(3-\tau))]}{8(1-\alpha)\left(1-\beta^{2}\right)-\alpha^{2} \beta^{2}} .
\end{aligned}
$$

Subsequently, we derive the optimal fee $(\alpha)$ set by e-tailer Y. The optimal fee cannot be derived analytically (similar to the main model) and we resort to a numerical analysis.

Using the above solution for the RA configuration, and the results from the main paper for the RR and AA arrangements, we solve for the equilibrium configuration. This equilibrium configuration is presented in Figure A2.

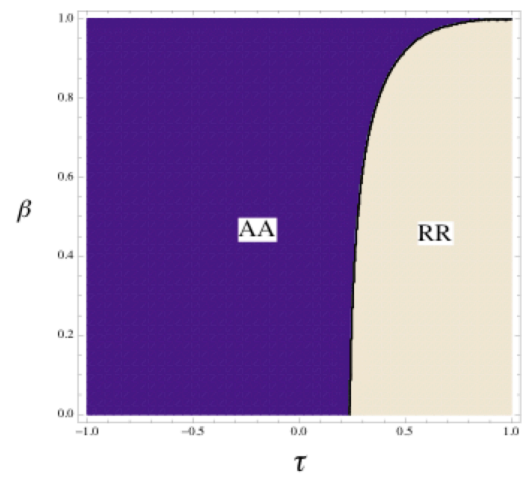

Figure A2: Channel structure when the manufacturer is the price leader in the RA configuration. 
From the figure, we can see that our main insights from Section 3 continue to hold. However, the hybrid configuration is no longer observed in equilibrium. Since the manufacturer is the price leader, and hence has more market power, an e-tailer no longer has an incentive to adopt the reselling arrangement in equilibrium when the competing e-tailer chooses the agency selling arrangement. Therefore, the asymmetric outcome does not appear in equilibrium. In other words, the increased market power of the manufacturer dominates the reduction in the retail-level competition (that results when one e-tailer resells).

\section{A5 Analysis with Alternative Demand Function}

In this appendix, to address the concern that our results are not driven by the specific demand function we choose in Equation (1) in the paper, we consider a demand system frequently used in the literature (e.g., Raju el al. (1995)), i.e.,

$$
q_{X}=1-p_{X}+\delta\left(p_{Y}-p_{X}\right) \text { and } q_{Y}=1-p_{Y}+\delta\left(p_{X}-p_{Y}\right), \text { where } \delta>0
$$

Note that as $\delta$ increases, the level of competition in the market goes up and the consumers become more sensitive to the price differential between the two e-tailers. In this manner, $\delta$ is analogous to $\beta$ in the original model, although they are on different scales $-\beta \in(0,1]$, whereas $\delta \in(0, \infty) .{ }^{14}$ Furthermore, the market size is constant in this formulation unlike in Equation (1) where the market size changes with $\beta$. In the subsequent discussion, we show that our major insights continue to hold even with this general demand system and are not driven by our specific demand systems specified in Equation (1).

We continue to use the same timing of the game as presented in Section 3. The solution of the channel game leads to the equilibrium channel configuration depicted in Figure A3(a). This figure corresponds to Figure 3 in the paper. We can clearly see that Propositions 1 and 2 continue to hold qualitatively (with slight differences in the exact shapes of the regions with different equilibria).

Next, we analyze the agency fee charged in equilibrium. We show the variation of the agency fee with $\tau$ in the Figure A3(b), which corresponds to Figure 5 in the paper. It is easy to see that this figure is very similar to Figure 5. The fee first increases in $\tau$ and then decreases. This finding is consistent with Proposition 3 in the paper.

Figure A3(c), demonstrates the variation in the agency fee with $\delta$ in the AA arrangement. The figure corresponds to Figure 6 in the paper, and shows that the fee monotonically decreases in $\delta$ when $\tau \leq 0$, and first increases and then decreases in $\delta$ when $\tau>0$. Therefore, Proposition 4 in the paper continues to hold. This figure is very similar to Figure 6 in the paper. However, we do not see the agency fee converging to 0 , as $\delta$ is small. For large values of $\delta$, the fee converges to 0 . (Note that large values of $\delta$ are similar to values of $\beta$ close to 1.)

The above analysis shows that our results are not driven by our choice of the functional form.

\footnotetext{
${ }^{14}$ Loosely speaking, large values of $\delta$ have a competitive effect similar to values of $\beta$ close to 1 . To see this, note that the original demand function used in the paper can be written as $q_{X}=\frac{1}{1+\beta}\left(1-p_{X}+\frac{\beta}{1-\beta}\left(p_{Y}-p_{X}\right)\right)$, and compare with $q_{X}=1-p_{X}+\delta\left(p_{Y}-p_{X}\right)$.
} 


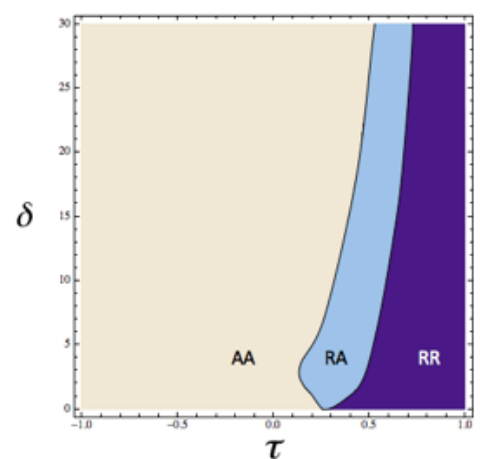

(a) Equilibrium channel configuration

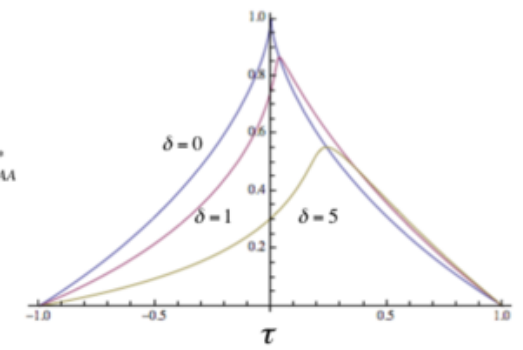

(b) Variation of agency fee with $\tau$

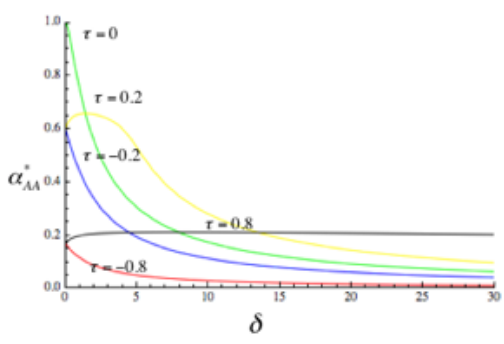

(c) Variation of agency fee with $\delta$

Figure A3: Illustrative figures for analysis with the alternative demand system

Furthermore, this analysis also alleviates the concern that some of our results might be driven by a decrease in market size (in the main model) as $\beta$ increases. All our main results continue to hold even when the market size is held constant indicating that the main forces driving our results are indeed the cross-effect and e-tailer competition. 